\title{
BRIDGING THE GAP BETWEEN THEORY AND PRACTICE FOR ADOPTING MEANINGFUL COLLABORATIVE BIM PROCESSES IN INFRASTRUCTURE PROJECTS, UTILISING MULTI-CRITERIA DECISION MAKING (MCDM)
}

\author{
SUBMITTED: September 2021 \\ REVISED: October 2021 \\ PUBLISHED: November 2021 \\ GUEST EDITORS: Nashwan Dawood, Farzad Pour Rahimian \\ DOI: $10.36680 /$ j.itcon.2021.043
}

\author{
Andrew Pidgeon \\ School of Computing, Engineering and Digital Technologies, Teesside University; \\ A.pidgeon@tees.ac.uk \\ Nashwan Dawood \\ School of Computing, Engineering and Digital Technologies, Teesside University; \\ N.n.dawood@tees.ac.uk
}

\begin{abstract}
SUMMARY: Existing research spanning academic and industrial literature shows that due to the ever-increasing number of descriptions of BIM on top of a saturation of standards methods and procedures, with little evidence on how to achieve goals for truly collaborative BIM, a gap is forming between theoretical and applied BIM, and thusly reducing the potential advantages and benefits of implemented BIM. Objectives set as part of this research, post systematic review of both academic and industrial literature were to firstly define a common meaning of what collaborative BIM is through the development of a syntax to support a hypothetical infrastructure project utilising academic and industry BIM experts. This was then followed by bringing to the front the inefficiencies in their current form and define how the fundamental parts of BIM are assigned and then prioritised both qualitatively and quantitively, in order to enhance information clarity (goals and objective achievement) and inconsistency reduction towards better ways of implementation. Conclusive findings derived from this research states that information management was determined by the focus group in being the key and top-level component in achieving collaborative BIM, which was determined via the contribution and development of an objective focused implementation framework adapted from the Analytical Hierarchy Process (AHP). This methodology increases the certainty of goal attainment for project team members, by presenting them with a dynamic qualitative and quantitative methodology that guides, determines and agrees the objective focus in an adaptable method through focal clarity of the intended use and what is required to be achieved through the adoption of collaborative BIM for a range of stakeholders. In summary, the research findings herein assert the need and benefit of objectifying collectively agreed focus on the desire of collaborative BIM including a range of stakeholders. Furthermore, inconsistencies towards agreements of standardisation and quality assurance are revealed, which is countered and supported by the developed novel methodology, in order to reduce the impact of such lack of consensus going forwards towards seeking better understanding and thus implementation of collaborative BIM.
\end{abstract}

KEYWORDS: Building Information Modelling (BIM), Multi-Criteria Decision Analysis (MCDA), Multi-Criteria Decision Making (MCDM), Analytical Hierarchy Process (AHP), Goals and Objectives

REFERENCE: Andrew Pidgeon, Nashwan Dawood (2021). Bridging the gap between theory and practice for adopting meaningful collaborative BIM processes in infrastructure projects, utilising multi-criteria decision making (MCDM). Journal of Information Technology in Construction (ITcon), Special issue: 'Construction 4.0: Established and Emerging Digital Technologies within the Construction Industry (ConVR 2020)', Vol. 26, pg. 783-811, DOI: 10.36680/j.itcon.2021.043

COPYRIGHT: (C) 2021 The author(s). This is an open access article distributed under the terms of the Creative Commons Attribution 4.0 International (https://creativecommons.org/licenses/by/4.0/), which permits unrestricted use, distribution, and reproduction in any medium, provided the original work is properly cited. 


\section{INTRODUCTION}

Building Information Modelling (BIM) has become a common approach when discussing the implementation of design and construction within Infrastructure projects over the last decade (Bargstädt, 2015). Barlish and Sullivan (2012) state further that it is very important that BIM has a 'clear definition' even before potential advantages are discussed and realised. Additionally, new processes alongside digital toolsets and cultural change management programmes aim to improve and transform traditional information management processes (Eastman et al, 2011), enhance engineering outputs and advance collaboration techniques (Penttilä, 2006). Digital technologies themselves can also support this opportunity, whilst at the same time removing legacy boundaries stemming from requiring teams to collocate at fixed geographical locations (Chinowsky and Rojas, 2003) and thus improving advancements in collaboration between wider stakeholders. In addition, there is an abundance of standardised BIM requirements, ranging from mandates and instructions from clients (HM Gov., 2011; Ollerenshawet al, 1997) to a plethora of BIM focused platforms (geometric and non-geometric), literature and reporting (Eppler and Platts, 2009) which highlight the multi-focused approach to ensuring BIM is sufficiently delivered at the Design and Construction stages. However, Bryson and Mobolurin (1995) suggests that although there is benefit in toolset development to proactively measure performance and outcomes, a 'robust methodology' must be applied to allow any obstacles to be outlined and dealt with. Collectively, advancements in the field of BIM implementation have been previously stated as having the ability to deliver '20\%' reduction in costs (HM Government, 2011) via 'Collaborative BIM', with Chahrour et al (2020) evidencing that from the use of model coordination and clash detection, savings of ' $\$ 15.2 \mathrm{M}$ ' were achieved via an applied case study, which was c. $20 \%$ of the overall construction cost of the project. Furthermore, (Holzer, 2007) states that this is due to BIM being a 'more accurate' way of working due to advantages such as its ability to embed stakeholders into a digital environment, utilise immersive technologies and benefit from the enhancements of efficient information exchanges. Leading on from this, and due to the progressive implementation of digital methodologies and BIM, multiple 'implementation strategies' have and are actively being produced with most directly instructed at a Government level by nations such as USA, UK, Denmark, Germany, The Netherlands and Singapore (Sielker and Allmendinger, 2018). These developed visions and strategies are generally complimented by standards, methods and wider procedural developments which have extended into deliverable processes within their respective design and construction infrastructure sectors respectively (UK BIM Alliance, 2020). In respect to the United Kingdom, the UK BIM Framework (UK BIM Framework, 2018) is supported by ISO19650-2:2018 (and other complimentary ISO19650 standards within the suite) which is an information management protocol reinforced with a complimentary UK Annex that enables project teams to develop and deliver a standardised approach to delivery of projects via collaborative BIM (BSI, 2018). This framework builds on the previous developments of the BIM Level 2 mandate (UK Government, 2011) as well as the BS1192:2007+2016 and PAS1192-2:2013 suite of standards, with its aspiration to drive efficiencies across the whole life cycle of an asset (BSI, 2013). However, there are also notable gaps between the theoretical underpinnings and it's practical application with Sebastian and Berlo (2010) stating that there is 'no common benchmarking' for organisations applying and thus implementing BIM. Furthermore, within the current international BIM standard referenced above, the planning and determination of goals/objectives is loosely and singularly set as a requirement within the 'pre-appointment BIM Execution Plan (BEP)' within Section 5.3.2b (BSI, 2018). This statement within the former simply requires the project to state a high-level 'set of objectives/goals for the collaborative production of information'. Moreover, these are typically captured in a table within the relevant section of the BEP, with their focus being expanded to only assign them as low, medium and high prioritisation, and no pointers towards implementation and alliance requirements focused on attainment. Furthermore, research by Eadie et al (2013) has shown that in terms of collaboration between teams utilising the BIM workflows it is better understood at the early stage of projects, with a general phasing out towards confusion through lack of understanding. Hore et al (2011) further supports this by stating that training of teams should be subsidised by the client, so that personnel have the education and thus ability to satisfactorily implement BIM practically through theoretical underpinning, with Arayci et al (2011) advising that this assists in extending collaboration 'across boundaries' of multiple stakeholders and is a positive in terms of Return On Investment (ROI). Further, evidence by Azhar et al (2012) states that a restrictor to achieving fully collaborative BIM is the 'interoperability issues' between the various software types and their formats (outputs). Jordani (2008) emphases that this causes a 'dramatic change' in the cultural working practice and sub-sequent coordination activities required to facilitate implementation and collaboration via BIM respectively. In addition, Doloi (2012) states that measured performance downfalls of projects are typically due to the complexity of the project combined with a vagueness in scope alongside the requirements and expectations from each of the team members. Further, 
Bargstädt (2015) affirms that measurements of adoption and maturity in being able to deliver BIM are overshadowed by the prioritisation of performance measures set within organisations business model indicators. In addition, Kagioglou et al (2001) state that Key Performance Indicators (KPI's) directly relatable to BIM are loosely defined and thusly rarely used, with Race (2012) determining that contributes to product liability issues as well as difficulties in the overall measurement of data compliance and benefits (Ibbs et al, 2007). Another element that is commonly referenced is that project managers may see the theoretical advantages of BIM being very attractive, but in isolation they don't translate themselves into tangible benefits without practically applied effort, coordination and a solid approach (Eadie et al, 2013). Jato-Espino et al (2014) have developed this further by stating that decision making directly in regard to construction is 'a key factor to achieve success in any discipline' and more so in respect to those that are 'handling large amounts of information' through data management, optimising process selection and responding to the complexity of multiple disciplines becoming coordinated with a unified objective. Furthermore, and most recently, a paper produced by Tan et al (2021) on the subject of current uses of MCDM alongside BIM states that an 'integrated decision-making approach' is the optimum way to target and increase the likelihood of achieving BIM objectives being realised, which involves rationalising data, ousting the 'potential ability' of targeted information management among key stakeholders (client, project managers, BIM managers, task team members etc.) and thusly reducing typical BIM 'adoption issues' (Pidgeon and Dawood, 2021). Bond et al (2008) supports this further by affirming that without an agreed and unified approach it is 'difficult for individuals to effectively articulate all of the objectives that underlay the problems with which they are faced', with Ellis (1970) calling this the 'test of importance' as a decision maker (or makers) must determine the direction a team should aim for, in order to increase the likelihood of achieving the objective. However, an important factor to appreciate is that there are numerously advantageous reasons for choosing to adopt BIM and Digital Engineering toolsets on top of mandatory requirements such as but not limited to, enhancing design coordination (Dossick, 2015), Cost Benefit Analysis (Chahrour et al, 2020), 4D construction phasing and scheduling (Da Silva et al, 2019), Advanced Information Management (Taylor, 2007) and Clash Avoidance (Akponeware and Adamu, 2017). Therefore, there is an advantage in exploring further the rationale behind the existing methods of how collaborative BIM is managed, measured and maintained, as well as defining the opportunities to define goal setting simply yet robustly, through objectification with a focus on achieving coordinated outcomes.

The sections which follow explore further the existing literature from both the perspectives of the underpinning academic and industrial literature respectively.

\section{LITERATURE REVIEW}

To provide a clear and robust theoretical underpinning of topics associated with the depth of research required, a systematic literature (Borenstein et al., 2009) view was undertaken across both academic and industrial literature to discover, extract and analyse data from a wide range of 'connected sources' (Baxter \& Jack, 2008). Moreover, to ensure that the literature review was not limited to a singular and thus limiting area of exploration, a 'collective/multiple' approach (Stake, 2005) was incorporated to form part of the design methodology. Additionally, and to further explorer the underpinning literature developments, the key terms following thematic analysis (Nowell et al, 2017) and a Boolean filtering process (Mulvihill and Brenner, 1968) which follow were those that were searched for within relevant subject titles via online academic research libraries. These libraries and repositories included Research Gate, Google Scholar, Elsevier and University Libraries with the condition applied that they must be written in the English language and linked to the application of BIM- those items which did not match these requirements were excluded from the systematic literature review as they were determined to be inappropriate and have the potential to instil ambiguity. This approach facilitates a wider outreach of data collection techniques and a more effective way of understanding both academic and industrial theories/applications, allowing a more detailed intrinsic review (Hart, 2001), which will shape the practical steps of the study. This additional factor is beneficial to examining multiple cases in order to gain further depth into the interlinked subjects and to 'explore a setting to order to understand it' (Cousin, 2005). This statement is also supported by Hart (2001) adding 'supplementary credibility' to the overarching applied methods and thus rounding of the explorative research process. In regard to and since BIM's inception, it has notably developed a wide- and far-reaching span of 'abbreviations, descriptions and definitions' (Barlish and Sullivan, 2012), which is on top of multiple supportive tools and methodologies for measurement and management of BIM projects. In regard to the maturity measurement and contrasts of BIM, the World Economic Forum (2016) has outlined a ranking system of 
digital maturity across nations who have a preference and focus on digitisation and innovations. Table 1 below shows this 'Network Readiness Index' matrix in order of positive developments made towards seeking consistent adoption of BIM.

Table 1. Network Readiness Index (Redrawn from World Economic Forum, 2016)

\begin{tabular}{|l|l|}
\hline Rank & Economy \\
\hline 1 & Singapore \\
\hline 2 & Finland \\
\hline 3 & Sweden \\
\hline 4 & Norway \\
\hline 5 & United States \\
\hline 6 & Netherlands \\
\hline 7 & Switzerland \\
\hline 8 & United Kingdom \\
\hline 9 & Luxembourg \\
\hline 10 & Japan \\
\hline 11 & Denmark \\
\hline 12 & Hong Kong SAR \\
\hline 13 & Korea, Rep \\
\hline 14 & Canada \\
\hline 15 & Germany \\
\hline$\ldots 24$ & Estonia \\
\hline
\end{tabular}

Methodologies which cover topics such as Key Performance Indicators (KPI's), Maturity Models (MM) and MultiCriteria Decision Analysis (MCDA)/MCDM alongside and supported by sub-processes within, such as the Analytical Hierarchy Process (Saaty, 1980), Preference Ranking Organisation Method for Enrichment Evaluation (PROMETHEE) (Opricovic, 1998), ELimination Et Choix Traduisant la REalité (ELECTRE) (Benayoun, et al, 1966) and Multi-Attribute Utility Theory (MAUT) (Keeney and Raiffa, 1976). Furthermore, industrial literature such as the international BIM standard for Information Management (BSI, 2018), was also included as part of the search set to further explore the gap between theoretical underpinning and practical application by industry and the advantages/disadvantages this may inherit in terms of inefficiencies and enhancements towards improved adoption (Eadie et al, 2013).

Moreover, the key search term titles which were inputted into the electronic libraries to discover pre-existing available research (in no particular order or importance) as developed through separate lead up research before this study undertaken by Pidgeon and Dawood (2021) were as follows:

- BIM goals and objectives;

- BIM measurement and management;

- Multi-Criteria Decision Analysis (MCDA)- linked to BIM; and

- Multi-Criteria Decision Making (MCDM)- linked to BIM.

These key terms aim to guide, support and give more clear direction towards the 'information searches' allowing a range of datasets to be analysis and critically reviewed (Tracy, 2010), which follows the 'seven step model' proposed by Onwuegbuzie and Frels (2016). In terms of visually defining the literature review searched process flow in light of the aforementioned methodology, Figure 1 below outlines the procedure undertaken alongside the initial number of returned literature findings for each of the respective key search terms used (including scan of the title, abstract and main body of the papers respectively). 


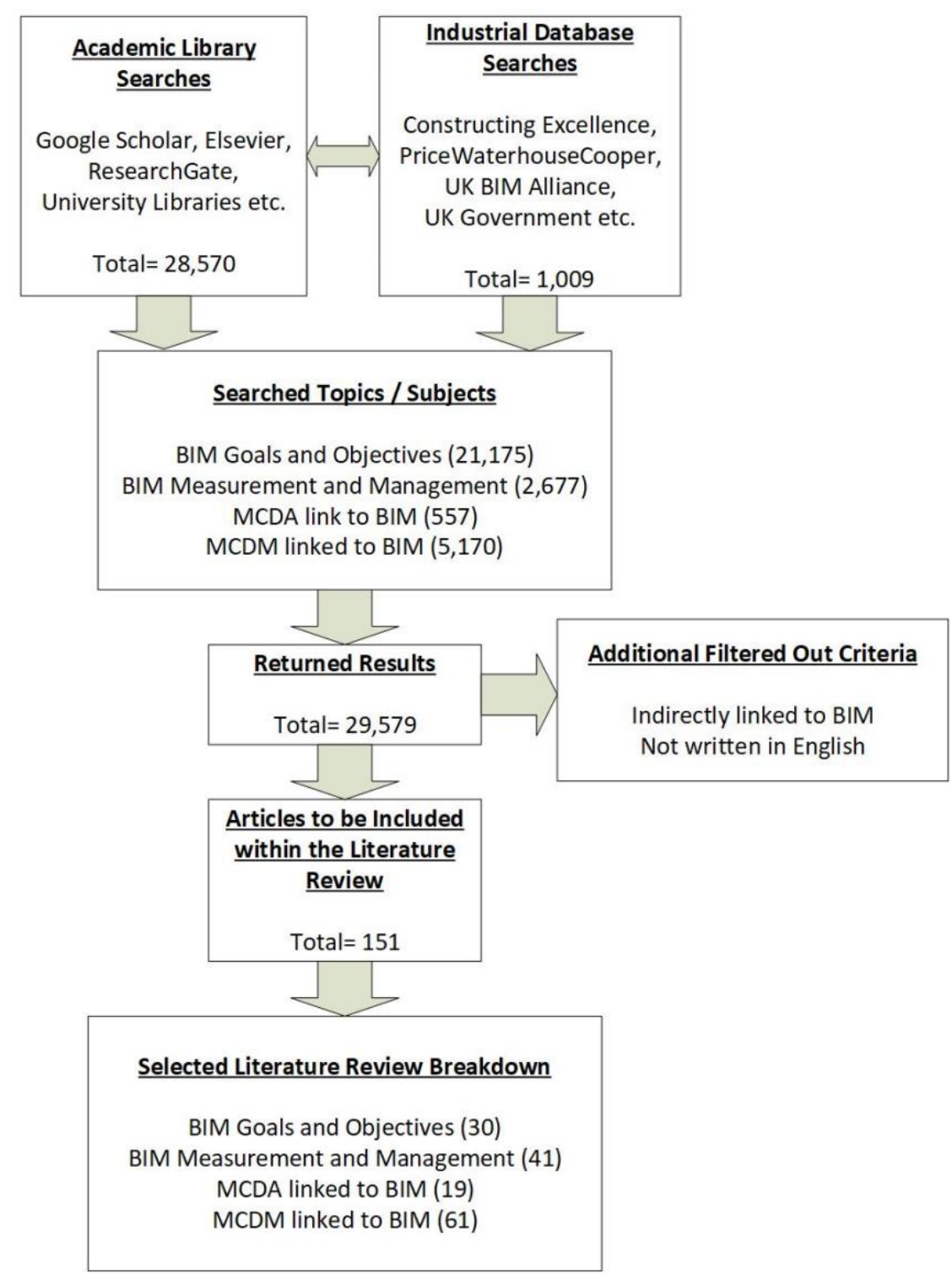

FIG. 1: Literature review- search flow process (PRISMA, 2020)

Continuing on from the search flow findings, Table 2 below extrapolates on the main headers for the key search terms outlined above in Figure 1 and focuses more directly the more appropriate filtered literature for examination in line with the initial requirements. These filtered and quantified findings following Boolean searched returns are utilised to improve the appropriateness and relevance of returned literature (DiCicco-Bloom and Crabtree, 2006) and form the basis of the selected literature topics.

Table 2. Summarised literature searched findings

\begin{tabular}{|l|l|l|l|}
\hline \multicolumn{1}{|c|}{ Key terms searched } & $\begin{array}{c}\text { \# Identified literature } \\
\text { (pre-filtered) }\end{array}$ & $\begin{array}{c}\text { \# Selected literature } \\
\text { (filtered) }\end{array}$ & $\begin{array}{c}\text { Post filtered percentage of } \\
\text { focus (\%) }\end{array}$ \\
\hline BIM goals and objectives & 21,175 & 30 & $19.9 \%$ \\
\hline BIM management and measurement & 2,677 & 41 & $27.1 \%$ \\
\hline MCDA (linked to BIM) & 557 & 19 & $12.6 \%$ \\
\hline MCDM (linked to BIM) & 5,170 & 61 & $40.4 \%$ \\
\hline Total & $\mathbf{2 9 , 5 7 9}$ & $\mathbf{1 5 1}$ & $\mathbf{1 0 0}$ \\
\hline
\end{tabular}


Furthermore, a 'post filtered percentage of focus' column has been added to provide visibility of the subject matter domination as part of the systematic literature review. Summarising on these results MCDM is most dominant at $40.4 \%$, followed in second place by BIM management and measurement at $27.1 \%$, with BIM goals and objectives in third place at $19.9 \%$ and MCDA in fourth place at $12.6 \%$ of total returned items. The intent and logic with this approach is to home in on the appropriate literature content which is best suited to the research through adding improved quality of the subject matter. Further, this filtering process utilising the Boolean search logic (Mulvihill and Brenner, 1968) enabled further clarity and the ability to remove any needless/non-contextual data so that the focused content is more appropriate to the research, and at a manageable number.

The sections which follow hereafter provide a descriptive overview and insight of evidence collected for the common individual measurement systems as part of the systematic literature review, with direct focus on each of the topics outlined as part of the core search structure.

\subsection{BIM Goals, Objectives, Management and Measurement}

Following the systematic literature review utilising the PRISMA flow (Page et al, 2020) for dataset extrapolation and selection, as collectively shown in Figure 1 above there were 23,852 research papers and industry reports on the subject of BIM goals, objectives and measures from the key terms searched through a Boolean filtering of the localised areas. Of these returned values, 71 were identified as being most appropriate in direction relation to BIM goals, objectives, management and measurement, with their application biased towards BIM implementation within the infrastructure design and construction environments. Furthermore, Barlish and Sullivan (2012) state that there is no 'dominant framework methodology' for measuring BIM which results in an inconsistency of tools used for comparison of case studies and thus success/failures across the infrastructure sector. In addition, Ibbs et al, 2007 agrees with this statement, by adding that there is an 'inconsistency of toolsets used', which is difficult to consistently measure the 'success and benefits' at the implementation stage of BIM across various stakeholders. In addition, at the time of writing there are a limited number of systems which allow sufficient 'measurement of the improvements' of BIM at the application stage as outlined by Succar et al (2012). Eppler and Platts (2009) advance on this further by outlining that overcomplexity has occurred due to the sheer 'abundance of BIM specific tools, books and media' which has somewhat resulted in oversaturation of the subject and reduced the availability of relative and reliable measurement toolsets. Additionally, a large number of conflicting aspects which are not limited to technical, economic and political spectrums within typical decision-based measurement systems further hinder management as a whole (Jato-espino et al, 2014). Moreover, Aljumaiah (2020) determined via research that for every ' $\$ 1 \mathrm{bn}$ invested' in infrastructure construction projects in the USA, $\$ 122 \mathrm{~m}$ of the gross cost was incurred waste 'linked to poor performance'. This is extended further by Aljumaiah (2020) in that measurement of BIM success results in 'one third' of projects being delivered on time and budget, with 45.8 \& believing this was a result of 'poor coordination costing' with little centralised measurement system(s) in place.

In regard to goal definition and measurement from the perspective of international BIM standardisation (ISO19650-2:2018), this information management framework outlines the requirement at a project execution level for 'a set of objectives/goals for the collaboration production of information'. However, other than this statement outlining that high level goals and objectives shall be captured within the 'Pre-Appointment BIM Execution Plan', it goes no further in defining and objectifying how goals will be achieved and delivered through BIM outputs. This is even in respect to the wider guidance frameworks produced by the UK BIM Framework (UK BIM Alliance, 2020) within guidance framework notes. In addition, and from an industrial literature perspective, all public government projects within the Governments Major Projects Portfolio (GMPP) are formally measured as required by the Infrastructure Project Authority (IPA) mandate set in 2011 and revised in 2021 (UK Government, 2011; IPA, 2021). This mandate along with its subsequent measurement methodology assigns 'confidence levels' which are collated and distributed annually within the Major Projects Report (IPA, 2016). However, as shown from previous research undertaken by Pidgeon and Dawood (2021), since the UK BIM Mandate (HM Gov, 2011) was implemented across 'all publicly awarded' projects from 2016 onwards, there has been a reduction in the confidence levels of projects being delivered in time, on budget and with reduced impact on other stakeholders, as summarised below in Figure 2. 
Figure 6: DCA Analysis 2013-2020

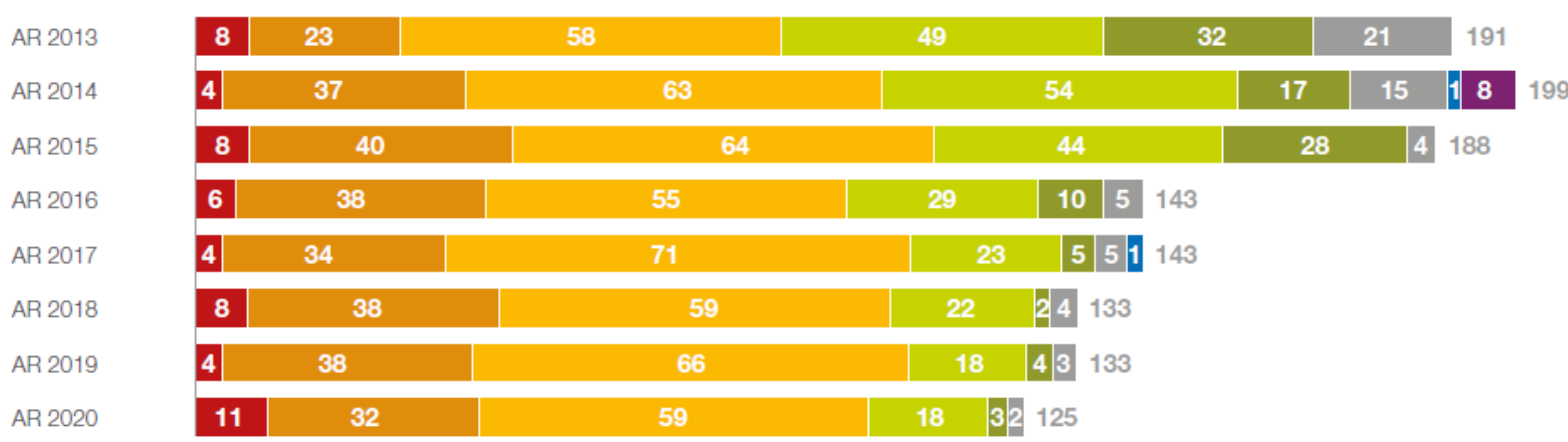

Red Amber/Red Amber Amber/Green Green $\square$ Exempt $\square$ Reset $\square$ No DCA

FIG. 2: IPA Delivery Confidence Assessment (DCA) (IPA, 2020)

Moreover, and in regard to the importance of measuring and managing projects, there is a clear potential benefit this field when focusing on transparent analysis of success through the use of BIM goals and objectives, with Lockamy III and McCormack (2004) stating that there is a 'great effectiveness' in having the ability to measure achieved goals and importantly, apply 'more ambitious ones' when success is managed, measured and achieved. Succar et al (2012) extends this further by reaffirming that without adequate measurement systems for BIM it becomes much more difficult for project teams to 'consistently measure their own success and failures'. Fortune (2006) adds to this statement by affirming that there is 'no whole project delivery review on cost performance', which means the Return On Investment (ROI) of BIM is 'difficult to ascertain' clearly. The aim and benefit of a clear, reliable and usable measurement systems is to provide 'feedback for improvement' and 'guidance for next steps' (Nightingale \& Mize, 2002, p. 19) as suggested in the former statements. However, Ustinovičius et al. (2018) reaffirms this as merely by stating BIM as a delivery mechanism it doesn't result in 'secured consistency' and therefore applying theoretical BIM without defining approaches attracts inefficiencies (Pidgeon and Dawood, 2021). Also, it is evidenced that when a large number of solutions (or options) are defined, the required evaluation and selection process may become extremely complex and difficult to handle (Cecconi et al, 2017).

Exploring this topic further, the ICE (2015) undertook a review of performance improvements on a Highways infrastructure framework and derived that there were typically three reoccurring 'typical issues' in achieving successful outcomes at a project delivery level which are:

- $\quad$ Measuring team performance (time and cost);

- Silo working; and

- Poor reliability for stage completion.

Furthermore, following the integration of Specific, Measurable, Agreed, Relevant and Time-bound (SMART) techniques (Doran, 1981) and refocusing on forward visibility whilst simultaneously limiting the 'short term focus', 90\% improvements were able to be achieved and shared across wider collaborative client frameworks. Succar et al, (2012) highlights that it is important that BIM performance metrics are 'accurate and adaptable across different industry sectors and organisations'; therefore scalability, cross-sector functionality and alignment with a standardised way of delivering BIM is key to success measures. Barlish and Sullivan (2012) research state that KPI's in construction largely differ to the outlined BIM requirements in terms of their focus and that they 'result in confusion'. Moreover, their research shows the four main areas of 'inconsistency' which result in barriers are, but are not limited to:

1. What should be measured?

2. How it should be measured?

3. What the sources of change are?

4. How to evaluate project success (or failure)? 
Cox et al (2003) advances on this further by stating traditional KPI's and measurement systems are 'complications of data' which failure to determine areas of success and are focused very much on biased particulars of outcomes such as health and safety and productivity (qualitative), as well as chargeable hours and project completion tasks (quantitative). These segregations of KPI success measures as formerly mentioned are also supported by Zuppa et al (2009) research into 'BIM success measures of construction projects'. Adding to the fundamental requirements which assist in ensuring that BIM is measured sufficiently in order to gain maximum benefit and transparency of the progress at the implementation stage, Chan and Chan (2004) tested eight measures which include in no specific order of preference:

- $\operatorname{Cost}^{*}$;

- Time*;

- Safety;

- Practitioners satisfaction;

- User satisfaction;

- Environmental performance;

- Profitability; and

- Quality*.

*Note: Those with an Asterix above were deemed post evaluation by Chan and Chan (2004) as having the most benefit in terms of ascertaining the success of construction projects.

It is also acknowledged by Sanvido et al (1992) that measures often are competing and alternating, which is largely 'dependent on stakeholders' priorities, commitments and goal requirement (Aouad et al, 2005). Rawlinson (2015) outlines that definition towards better Plain Language Questions (PLQ's) are 'needed to understand the key components' of the measurement systems and requirements. Furthermore, McKinsey (2020) outlined that time and cost overruns were perceived as 'normal' by industry with a maximum EBIT (Earnings Before Interest and Taxation) in construction being capped at around ' $5 \%$ '. In terms of BIM execution and returning on financial investments made towards staff upskilling, new process adoption and technology demands, Farmer (2016) states that construction is operating in a 'survivalist business model', which reaffirms earlier findings by Egan (1998) in that a rethinking of objective measurement and goal attainment is imperative if the delivery of BIM and thus construction are to be efficiently delivered in the future (but also at the here and now).

Several measurement systems have been developed for BIM through a concerted range of academic and industrial input such as BIM Measurement Methodology (BMM) Framework (PriceWaterhouse Cooper, 2018), BIM Proficiency Matrix (BPM) (Indiana University, 2009), Interactive-Capability Maturity Model (I-CMM) (Suermann, Issa, \& McCuen (2008) and BIM Quick Scan (Sebastian and Berlo, 2010) and integrated BIM (iBIM) (Bew et al, 2008). Table 3 below outlines these measurement systems and their focused areas in the context of their application for greater transparency and outlining their individuality respectfully. These methodologies were those most often cited when undertaking the initial key terms search and post filtered analysis as part of the systematic literature review.

Table 3. Common BIM measurement systems

\begin{tabular}{|l|l|l|}
\hline Measurement System & Citation & Focus Area Description \\
\hline $\begin{array}{l}\text { BIM Measurement Methodology } \\
\text { (BMM) Framework }\end{array}$ & $\begin{array}{l}\text { PricewaterhouseCoopers (PwC), } \\
2018\end{array}$ & $\begin{array}{l}\text { Eight phased approach to measuring Health and } \\
\text { Safety etc. }\end{array}$ \\
\hline BIM Proficiency Matrix (BPM) & Indiana University, 2009 & $\begin{array}{l}\text { BIM Contactor focused tool for assessing the } \\
\text { proficiency of contractors capabilities }\end{array}$ \\
\hline $\begin{array}{l}\text { Interactive-Capability Maturity } \\
\text { Model (I-CMM) }\end{array}$ & $\begin{array}{l}\text { National BIM Standard } \\
\text { (NBIMS), 2007 }\end{array}$ & $\begin{array}{l}\text { Determines the maturity of BIM project v the } \\
\text { required criteria attainment }\end{array}$ \\
\hline BIM Quick Scan & Sebastian and Berlo, 2010 & $\begin{array}{l}\text { Supply chain selection and to gain further } \\
\text { improvements and innovations }\end{array}$ \\
\hline
\end{tabular}


To gain a deeper insight into the methodologies described in Table 3 above, the section which follows expands upon these in further detail, showcasing existing traditions of measuring construction projects transparently and succinctly, typically aligned with BIM requirements.

\subsection{Multi-Criteria Decision Analysis (MCDA) and Multi-Criteria Decision Making (MCDM)}

MCDA is a methodology which has the ability to support, develop and enhance 'participatory and collaborative processes' (Marttunen et al. 2015). It facilitates a systematic approach to support the analysis of 'multiple criteria, objectives and results' (Belton and Stewart, 2002), with the ability to focus holistically on varying opinions, priorities and datasets in both a qualitative and quantitative manner (Gregory et al, 2012). Moreover, multi-criteria decision methods have the ability to support decision-makers faced with the 'evaluation of alternatives' (Cecconi et al, 2017), with Jalilzadehazhari and Johansson, (2019) adding that 'multiple objective optimisation' can be supported by MCDM, and thus increasing the dynamism of decision-making requirements. The applied potential means that this methodology can become a powerful tool to assist in selecting their criterion and priorities across a wide range of infrastructure 'construction problems' (Espino et al, 2014). Further, Kabir et al (2014) states following their research into the suitable benefits of applied MCDM that systems do provide 'demonstrable advantages' with Kiker et al (2005) adding that due to their diversification some are 'less difficult' to adopt and gain tangible benefits from their simplistic nature.

In terms of outlining a simplified explanation of MCDM, Tavares et al (2007) outlined the basic process flow with a focus on 'problem analysis' aimed towards seeking goal attainment or equally issue resolution, as shown below in Figure 3.

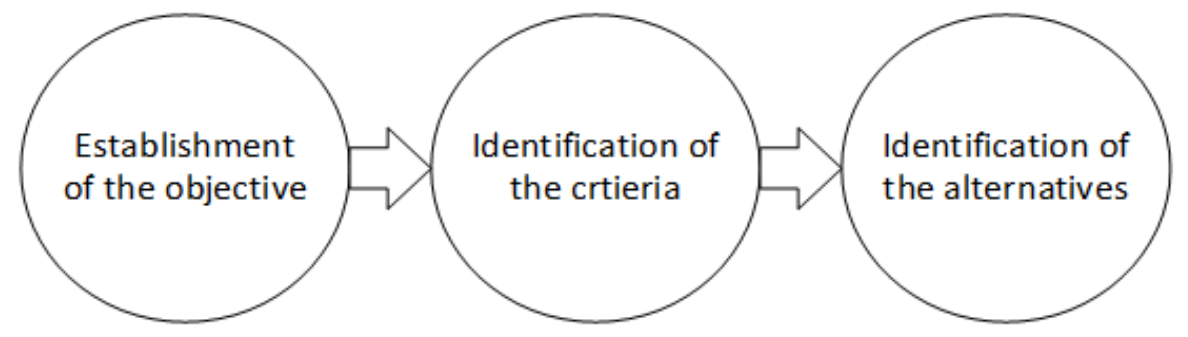

FIG. 3: Three main steps of the MCDM model (Tavares et al, 2007)

Furthermore, MCDA techniques can be used to support 'inclusive stakeholder participation' (Marttunen et al. 2015), and in respect to deeper strands of MCDA, can be focused onto more finite opportunities through the use of developed methodologies. However, although there are subtle differences in the system's unique development and structure, Belton and Stewart (2002) believe that across these various opportunities there are three common yet fundamental areas of their architecture. These are:

1. Problem identification and structure.

2. Development and implementation of the preference model.

3. Creation of the output tasks.

Within their research, Tan et al (2021) found that although MCDM techniques with BIM have been growing applied (exponentially in fact) since 2009, they tend to have been typically focused on applying the methodology more often at a limited operational level due to difficulties in areas such as 3D modelling data and issues with 'information uncertainty' (Volk, et al. 2014). Further, application has tended to be reoccurring in common focal areas such as optimising maintenance regimes (Chou, 2008), selecting construction materials (Lin et al, 2008) and supply chain assessment (Marzouk, 2010), which in fact limits the ability to apply more beneficial focus on the varied opportunities. Expanding on this further, Ishizaka and Siraj (2017) have shown that MCDM has the benefit and is clearly able to focus lots of variable input data into a single and unified output indication, with them performing well when dealing with risk and/or uncertainty. However, Salgado et al (2009) advises that although MCDA methodologies create an advantage to outlining the supportive decision-making requirements there is still an underlying failure to the 'nature of decision making'. Munda (2004) reaffirms this statement, by adding that this may actually invalidate the results of any such MCDA activity and/or its results. 


\section{METHODOLOGY}

This section explores the sub-techniques within the MCDA/MCDM methodologies as outlined within previous research by the authors of this paper, which were attained via the returned key searched terms and forms part of the feedback gained after undertaking the systematic literature review and analysing the core findings.

Reflecting on these initial literature findings, 80 directly relatable papers were analysed as part of the Boolean filtered key findings as part of the systematic literature review in regard to MCDA/MCDM. Moreover, examination found that the most common items as subsidies of MCDM in terms of measurement methodologies and systems directly linked to BIM and project application were AHP (56), PROMETHEE (8), ELECTRE (7) and MAUT (9), with the number in brackets determining the number of suitability relevant reports returned. Moreover, and in reaffirming support of this, Taha and Daim (2013) similarly outlined that MCDM includes numerous methodologies with some of the 'most established' of approaches in respect to adoption being as follows:

- Analytical Hierarchy Process (AHP) (Saaty et al, 2007)

- Preference Ranking Organisation Method for Enrichment Evaluation (PROMETHEE) (Opricovic, 1998)

- $\quad$ ELimination Et Choix Traduisant la REalité (ELECTRE) (Benayoun et al, 1966)

- Multi-Attribute utility Theory (MAUT) (Keeney, 1974)

Belton and Stewart (2002) describe the 'three core elements' of MCDA, which are dominant in all of the methodologies above (including MCDM) which are as follows:

1) Value measurement

2) Goal, aspiration or reference level models

3) Outranking models (pairwise)

Furthermore, Table 4 below describes and summarises the total filtered number of methodologies investigated and returned, in terms of their purpose and description, as well as their targeted use and functional benefits in a comparative way.

Table 4. Description of MCDM methodologies

\begin{tabular}{|l|l|l|}
\hline Name & Description of use & $\begin{array}{l}\text { \# Directly linked to BIM in } \\
\text { infrastructure application }\end{array}$ \\
\hline Analytic Hierarchy Process (AHP) & $\begin{array}{l}\text { Structuring and organisations complex } \\
\text { decisions }\end{array}$ & 56 \\
\hline $\begin{array}{l}\text { Preference Ranking Organisation } \\
\text { Method for Enrichment Evaluation } \\
\text { (PROMETHEE) }\end{array}$ & $\begin{array}{l}\text { Outranking method via comparative } \\
\text { analysis of alternatives (preference } \\
\text { based) }\end{array}$ & 8 \\
\hline $\begin{array}{l}\text { ELimination Et Choix Traduisant la } \\
\text { REalité (ELECTRE) }\end{array}$ & $\begin{array}{l}\text { Outranking method via comparative } \\
\text { analysis of alternatives (best } \\
\text { alternatives) }\end{array}$ & 7 \\
\hline Multi-Attribute Utility Theory (MAUT) & $\begin{array}{l}\text { Comparative risk and uncertainty biased } \\
\text { decision making }\end{array}$ & 9 \\
\hline & \multicolumn{1}{|l|}{ Total }
\end{tabular}

In summary, Table 4 above shows that the dominant MCDM methodology used at the project application level supporting the measurement of BIM applications is AHP with 70\%, followed by MAUT (11.25\%), PROMETHEE $(10 \%)$ and ELECTRE (8.75\%).

The section which follows describes further the MCDM methodologies as expressed above in Table 4, as well as the notable mathematical differentiators and their physical distinctions between the various types available which highlights their individual characteristics, their mathematical logic/reasoning as well as referencing evidence into their respective applied uses. 


\subsection{Design and Procedure}

The next phase of this research study is aimed at utilising both industry (design and construction) and academic experts to collectively determine the criteria and alternatives for collaborative BIM, feeding into the AHP pairwise matrices methodology. Further, the design and procedure aim to validate the findings through a two-part data collection activity through the use of semi-structured data collection techniques (questionnaire and interview), in order to ultimately ascertain how BIM objectives are defined, measured and managed (in respect to reducing the inefficiencies of collaborative BIM). The purpose of the data collection methodology of this research following a systematic literature review is to apply objective focus on the practical decision-making requirements, alongside 'goal attainment' (Saaty, 2007). Through the use of both qualitative and quantitative methods, two semi-structured interviews were undertaken through the utilisation of a congregated subject matter expert sample (or focus group), which input to the criterion, alternatives and fundamental scales (prioritisation values) and thus validate the schema proposal respectively. Further, normalisation the results was undertaken to firstly collect individuals inputs following the 'separability condition', and to then collate the findings as part of the group consensus through globalisation following the 'unanimity condition' (Felix, 2015). In addition, the aforementioned schema is developed to assist in defining the overarching process flow of the methodology purpose, with complimentary values that are applied to an AHP pairwise $5 \times 5$ matrix in respect to achieving collaborative BIM on a hypothetical infrastructure project. Moreover, the proposed measurement framework (AHP) is best positioned due to its wide and trusted application in determining MCDM techniques, for mostly 'planning and resource allocation' as well as 'conflict resolution' (Saaty, 1987). As evidenced in the initial literature review findings, AHP has been validated across several construction biased mediums due to its simplicity, its qualitative to quantitative nature and the added benefit of housing consistency tools within its formation- therefore deemed a sound choice for multiple stakeholders collaborating on a decision making in a complex area such as collaborative BIM. Furthermore, its direct link with construction projects and BIM as well as a fact evidenced by Espino et al (2014) that AHP has also been applied mostly due to its 'simplicity of application and flexibility'. However, and before the pairwise development of parts 1 and 2 respectively with participants, a proceeding step was to confirm and create a common benchmark through the means of a syntax of what the focus (or objective goal) is in regard to its description. Therefore, in terms of this study and in light of findings from the literature review, collaborative BIM shall be the leading focal point of the MCDM problem statement (focus question) and in the context of this research collaborative BIM is to be known as follows:

Collaborative BIM is an integrated process that enables collective stakeholders to assess, plan and execute a project across any stage of its lifecycle by utilising digital technologies in a virtual and shared environment, underpinned by people, processes and procedures. Efficient, effective and transparent transfer of information is fundamental in reducing errors and cost overruns, improving the quality of exchanges between multiple stakeholders, and towards gaining advantage from toolsets, innovations and enhanced governance methodologies.

In advance of the above statements, the core measurable objectives of this research are:

1) Undertake a systematic literature review, that provides a robust theoretical underpinnings topics associated with the depth of research required.

2) Develop a syntax that states what the meaning of collaborative BIM is for the hypothetical infrastructure project.

3) Determine the core underpinning criteria and alternative qualitative values of what the objective goal consists of, for collaborative BIM.

4) Define and rank the weighted values given for the criteria and alternatives in respect to collaborative BIM.

5) Induce and utilise an AHP pairwise matrix that enables qualitative and quantitative prioritisation based on consolidated as group perspectives.

6) Outline which areas of collaborative BIM are consistently/inconsistently assigned, as well as those elements which are of upmost importance in terms of prioritised weighting factors.

7) Collectively of points 1-5 above, develop a novel, objectively focused qualitative and quantitative weighted/prioritisation methodology for collaborative BIM.

The next section outlines the schema development process and the steps taken ranging from the initial data capture through to analysis and conclusion of the compiled pairwise matrix. 


\subsubsection{Schema Development Process}

The qualitative research (Sandelowski, 2004) as part of this research which underpins the schema development process and includes multi-stakeholder engagement and inclusion is aligned with previous research findings by Macharis et al (2004). This approach focuses on the analysis of multicriteria decision making when introducing both a complex problem and diverse range of participants. Following this similar methodology, the high-level plan for the schema process within this research proposal is as follows:

1. Identify the participants across design, construction and academia stakeholder groups (five from each) to be included as part of the focus group.

2. Determine the focus (or objective goal) with a supported syntax.

3. Develop a two-part data collection technique; 1) semi-structured questionnaire (criteria and alternatives development plus measurement insight) 2) semi-structured interview (for individually assigning weighted fundamental scales (eigenvalues) to the criteria and alternatives).

4. Execute the data capture exercise with participants (step 1).

5. Review and select the most common criteria and alternatives for addition to the pairwise matrix.

6. Undertake the data capture exercise (focus group interview) with participants to destine the weighted numerical values (pairwise eigenvalues) (step 2).

7. Consolidate and normalise the feedback received from the focus group semi-structured interview, into a singular 5 x 5 AHP matrix.

8. Analyse and conclude the results both qualitatively and quantitatively for the defined prioritisation values.

Moreover, the eight steps outlined above are shown visually in a swim-lane diagram within Figure 4 below, forming part of the research development processes rationale.

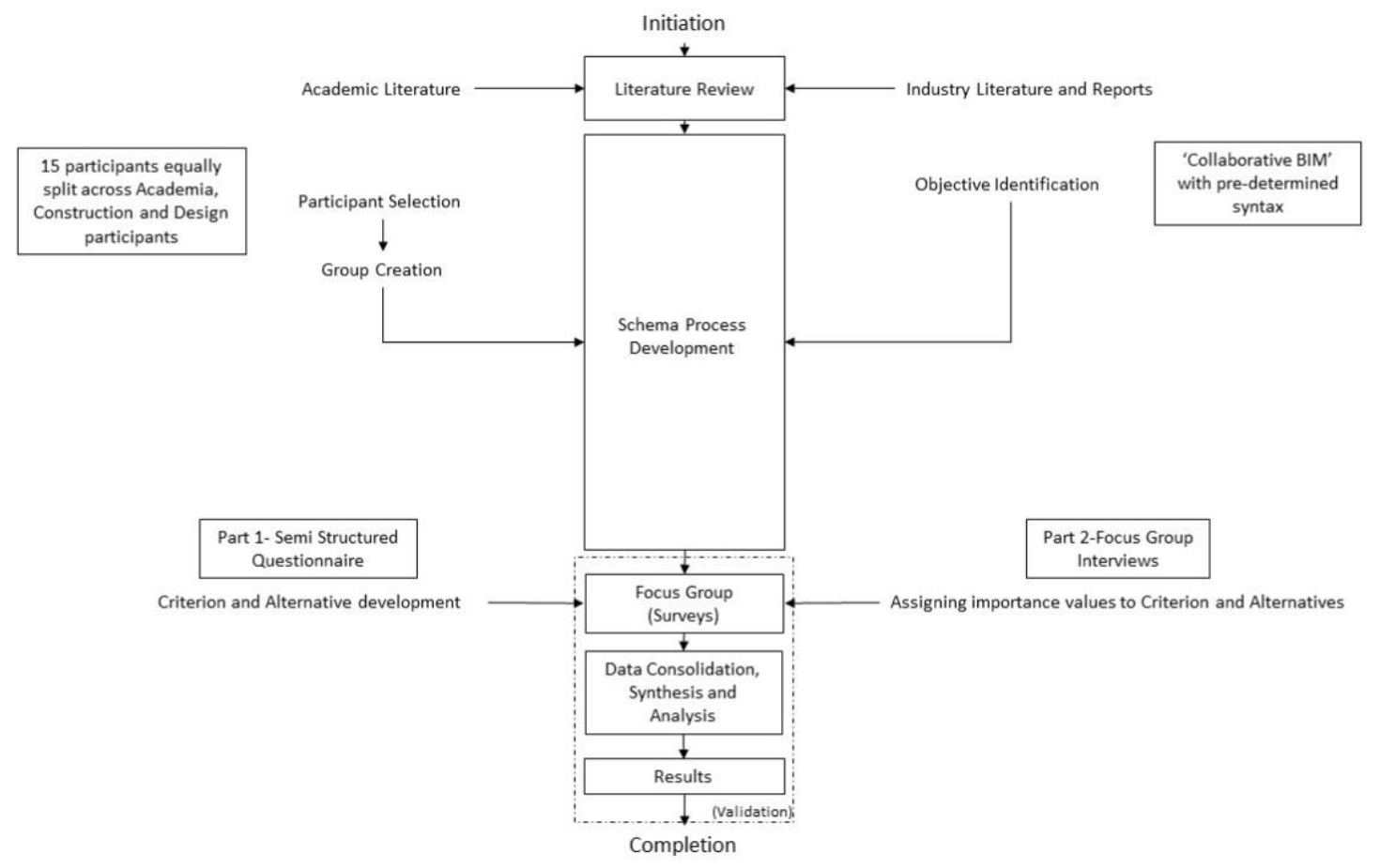

FIG. 4: Research flow

Adding further detail to the research development process aforementioned, an information process diagram as shown in Figure 5 below captures the linear flow of each step for attaining data inputs from each respondent with focus on the ultimate goal of MCDM. 


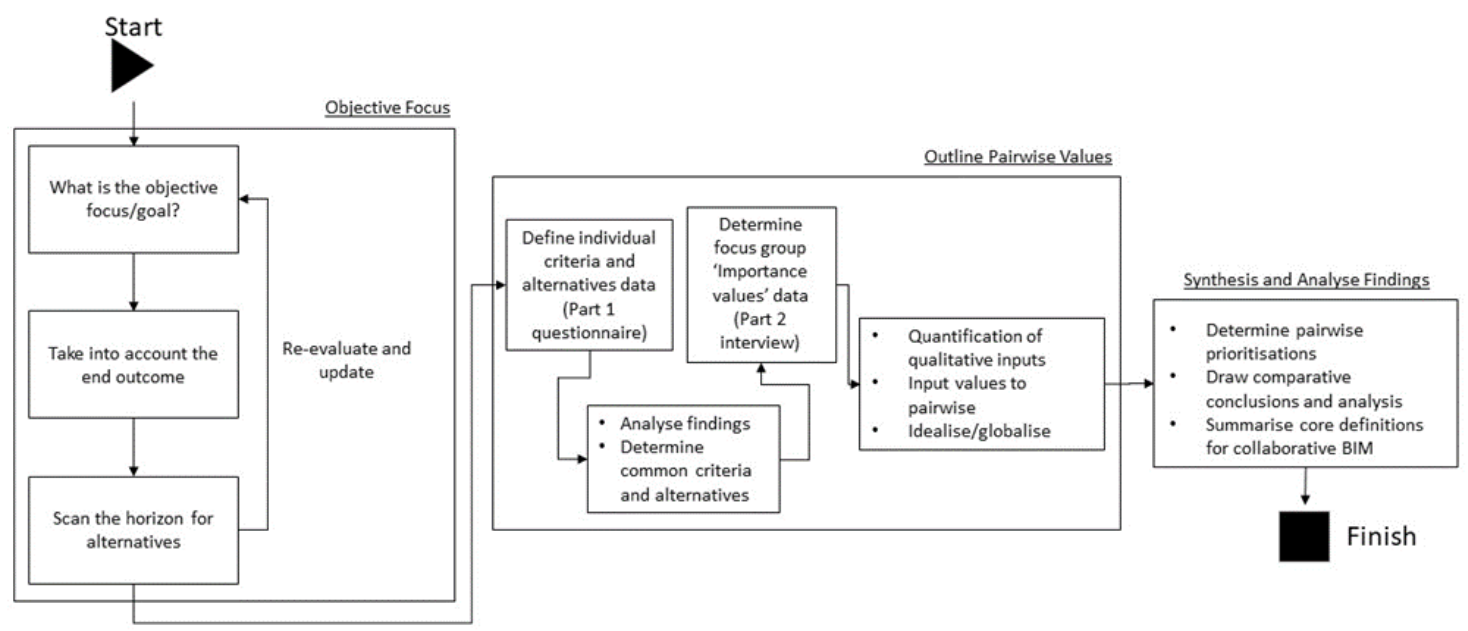

FIG. 5: Schema flow

A summary of each data collection and thus focal area, alongside the technique applied, is outlined below in Table 5 to include transparency of the 'analysis methods' as stated by Braun and Clarke (2006).

Table 5. Data collection summary

\begin{tabular}{|c|c|c|c|}
\hline Data collection stage & Data collection method & Focus Area & Participants \\
\hline Part 1 & $\begin{array}{c}\text { Survey } \\
\text { (semi-structured) }\end{array}$ & $\begin{array}{c}\text { Defining the criteria } \\
\text { and alternatives }\end{array}$ & $\begin{array}{c}\text { Academic (5no.) } \\
\text { Design (5no.) } \\
\text { Construction (5no.) }\end{array}$ \\
\hline Part 2 & Focus Group Interview \\
(semi-structured) & $\begin{array}{c}\text { prioritisation/weighting } \\
\text { of criteria and } \\
\text { alternatives }\end{array}$ & $\begin{array}{c}\text { Academic (5no.) } \\
\text { Design (5no.) } \\
\text { Construction (5no.) }\end{array}$ \\
\hline
\end{tabular}

In regard to data collection for parts 1 and 2, a robust workflow developed by Foddy (1994) was utilised to assist in regulating the validation of the survey questions, prior to them being directed towards the stakeholders both as part of the 'self-administered and research administered' technique (Wolf, 2011).

\subsubsection{Stakeholder Participant Mapping and Selection}

Almost all decision making involves people and to this point will statistically result in numerous 'conflicting points of view' (Govindan and Jepsen, 2016). Therefore, it is vitally important that a spread of stakeholders for those who would typically be involved in collaborative BIM is included to ensure the research validation covers design, construction and academic inputs for a wider data set. This is to ensure that there is no foreseen bias towards a single entity, and thus a singularity in terms of feedback generated, analysed and asserted, with Gudlaugsson et al (2020) stating that initial analysis of stakeholder selection is required, to 'recognise conflicts' as well as harmonise relationships. However, a point to note is that previous interviewed stakeholders utilised as part of a preceding study by Pidgeon and Dawood (2021) from design and construction sectors are continued within this research methodology. This is to draw a clear and consistent baseline from previous research findings and to generate further diversification by including academic experts in the field of BIM.

In addition, Phillips and Phillips (1993) outline that by integrating a range of diverse stakeholders 'decision conferencing' can be achieved through 'collective integration' via the use of digital tools and platforms. Adding transparency of the participant sample, a summary is provided below in Table 6 to reaffirm the inclusivity, diversity and the targeting of stakeholder selection, alongside their individual experience as part of the "probability sampling' technique (Fox, 2010). This technique includes 'framing, size, appropriation and suitability'. Furthermore, a key requirement in achieving improved 'rigor and credibility' (Tracy, 2010) is realised by assigning a search condition towards participant selection in that a minimum requirement for each participant to qualify means they must have a minimum of 10 years' professional experience of operating with BIM, and similar virtual design and construction principles. 
Table 6. Participant inclusion summary

\begin{tabular}{|c|c|c|c|c|}
\hline Stakeholder group & $\begin{array}{l}\text { Percentage } \\
\text { split }\end{array}$ & $\begin{array}{l}\text { Participant } \\
\text { reference } \\
\text { number }\end{array}$ & Participants title & $\begin{array}{l}\text { Years of } \\
\text { experience }\end{array}$ \\
\hline Academia & \multirow{5}{*}{$33 \%$} & $\mathrm{P} 1$ & Professor & 20 \\
\hline Academia & & $\mathrm{P} 2$ & Professor & 28 \\
\hline Academia & & P3 & Professor & 33 \\
\hline Academia & & $\mathrm{P} 4$ & Professor of Construction Management & 40 \\
\hline Academia & & P5 & Professor of Digital Construction & 12 \\
\hline Construction & \multirow{5}{*}{$33 \%$} & $\mathrm{C} 1$ & BIM Manager & 22 \\
\hline Construction & & $\mathrm{C} 2$ & Senior Project Manager & 22 \\
\hline Construction & & C3 & BIM Consultant & 35 \\
\hline Construction & & $\mathrm{C} 4$ & Project Manager & 30 \\
\hline Construction & & $\mathrm{C} 5$ & Deputy Regional Chief Engineer & 17 \\
\hline Design & \multirow{5}{*}{$33 \%$} & D1 & BIM Consultant & 12 \\
\hline Design & & D2 & BIM Manager & 10 \\
\hline Design & & D3 & Project Information Manager & 10 \\
\hline Design & & D4 & Operations Director & 21 \\
\hline Design & & D5 & Business Unit Director & $30+$ \\
\hline
\end{tabular}

The inclusion of this broader stakeholder group spanning academia, construction and design attempts to improve knowledge, inputs and opinions (Tracey, 2010), as well as defining the common underpinning definition of what collaborative BIM is and what it is upheld and supported by, including prioritisation of said themes. This conversion from qualitative inputs (written descriptors) to quantitative assignments (numerical values) will enable the collective groups inputs to be reviewed and shown within a unified matrix (averaging all contributions for collective gain) and provide a measurable weighting, supporting a clearly defined measurement system. Finally, it is important that all participants involved in the sample group are aware of the common syntax of the predefined question and also the requirements throughout the data collection process, which are included and outlined in plain language in the following sections.

\subsection{Part 1- Structure of Questions}

The hierarchical input structure within the AHP framework requires three levels determining to facilitate and populate the decision matrix which are Focus (objective/goal), Criteria and Alternatives, Also as noted above, a predetermination of the focus (objective/goal) in terms of the ultimate question has been predetermined as collaborative BIM, in respect to a hypothetical infrastructure project which stakeholders are engaged in as part of the research study. Additionally, and to gain further insight from the participants, a third question was added which queries the current measurement methodologies which underpin the descriptors given for criteria and alternatives in respect to collaborative BIM.

An electronic and interactive online tool, utilising Microsoft Forms, was customised to enable multiple stakeholders to be issued with a singular, electronic questionnaire, promoting consistent collection of data as well as streamlining the consolidation of results for further analysis. The questions proposed to each participant were categorised and designed as follows in each sub-section. 


\subsubsection{Criteria Development}

In order to populate the pairwise matrix and determine the importance headings which are eventually given eigenvalues, criteria are required to be developed in order to shape and support the objective focus of the hierarchical AHP network.

Therefore, a criteria development question was created in order to give the participant clarity and instruction, with the interviewer acting as an observer utilising the semi-structured data collection technique (De Vaus, 2002). The first question to ascertain the five criteria were as follows:

"In respect to collaborative BIM and the description provided previously, imagine we (the project stakeholders) are hypothetically involved in an infrastructure project and we are wanting to deliver a project via a collaborative BIM approach.

From your perspective what are the five main constituent parts (most important factors) which underpin this requirement, with respect to the hypothetical infrastructure project?

For example, and in support of your answers to this question, if the focus (objective) was 'smartphone selection' then criteria (or importance factors) for this might be the 'cost, battery life, applications.

The image attached within the last section may be useful in supporting your answer to this question".

\subsubsection{Alternatives Development}

Similar to the criteria development above, alternatives are required in order to populate the pairwise matrix and add further detailed options to the AHP network, which will be used when assigning eigenvalues (numbers in terms of relative importance) as part of the next phase of data collection (part 2). However initially the question to ascertain the five alternatives as sub-elements to the predetermined question were as follows:

"Adding to the previous question and sitting underneath the criteria definitions, what are the five alternatives (subimportance factors) from your perspective on this hypothetical infrastructure project?

For example, if the focus (objective) was 'smartphone selection' and if the criteria below were 'cost, material, applications' then alternatives might be 'weight, aesthetics, data allowance'.

The image attached may be useful in supporting your answer to this question".

\subsubsection{Supporting Material}

To ensure that further clarity was provided to each respondent who was participating in the semi-structured interview(s), a $5 \times 5$ matrix example as shown below in Figure 6 was added as supportive clarity to the process flow and information required from the collective participants.

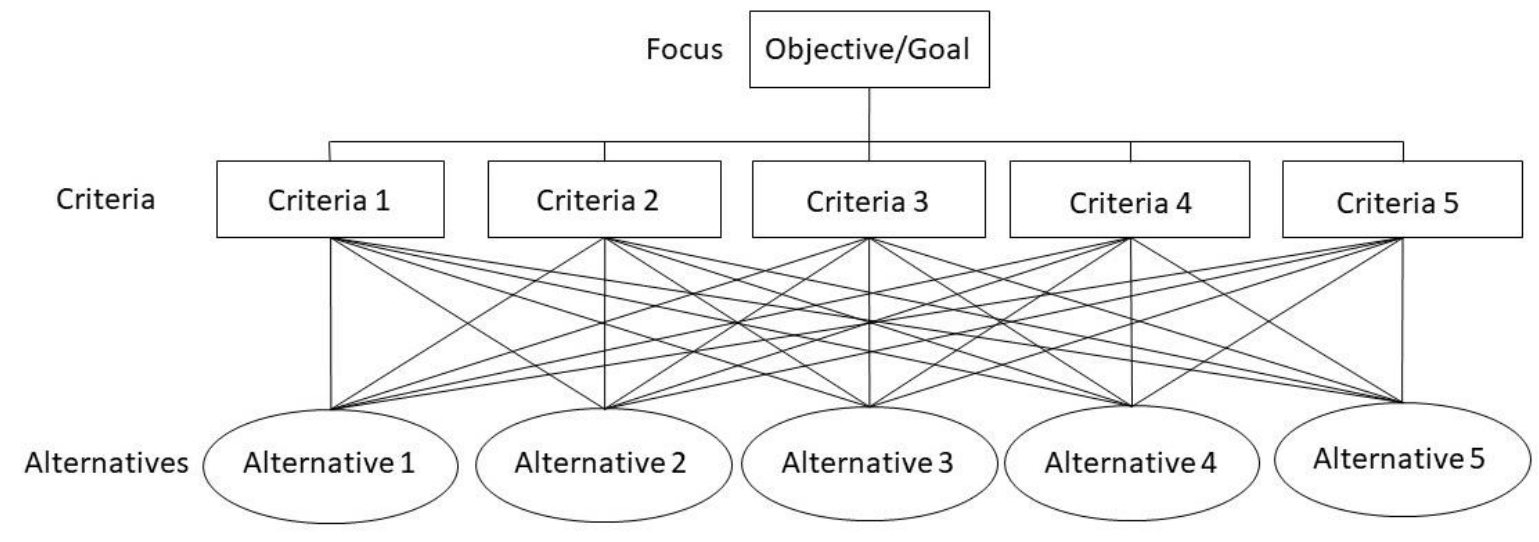

FIG. 6: Pairwise $5 \times 5$ matrix (example of basic structure)

\subsection{Pairwise Importance Methodology}

Following on from the part 1 semi-structured data collection survey to ascertain the individual criteria and alternatives (relevance) for the objective focus (collaborative BIM), a second stage (part 2) survey interview as a 
group exercise was undertaken in order to assign individual prioritisation values to the unified and corresponding criteria and alternatives (post consolidation).

The mode of attaining these valuations is via the 'research-administered' technique (Wolf, 2011), which will utilise the fundamental scales of the AHP structure in determining respondents opinions on the power of one element versus another.

This fundamental scaling applied was directed only towards the odd values of the absolute scale $(1,3,5,7,9)$ in order to retain simplicity and clearer definitions on the expectations from each participants, with a collective group agreement focus. Further, descriptions of these importance values are represented below in Table 7.

Table 7. Fundamental scaling (redrawn from Saaty, 2008)

\begin{tabular}{|c|c|c|}
\hline $\begin{array}{l}\text { Intensity of importance on an } \\
\text { absolute scale }\end{array}$ & Definition & Explanation \\
\hline 1 & Equal importance & $\begin{array}{l}\text { Two activities contribute equally to the } \\
\text { objective }\end{array}$ \\
\hline 3 & $\begin{array}{l}\text { Moderate importance of one over } \\
\text { another }\end{array}$ & \multirow[t]{2}{*}{$\begin{array}{l}\text { Experience and judgement strongly } \\
\text { favour one activity over another }\end{array}$} \\
\hline 5 & Essential or strong importance & \\
\hline 7 & Very strong importance & $\begin{array}{l}\text { An activity is strongly favoured, and its } \\
\text { dominance demonstrated in practice }\end{array}$ \\
\hline 9 & Extreme importance & $\begin{array}{l}\text { The evidence favouring one activity } \\
\text { over another is of the highest possible } \\
\text { order of affirmation }\end{array}$ \\
\hline $2,4,6,8$ & $\begin{array}{l}\text { Intermediate values between the two } \\
\text { adjacent judgements }\end{array}$ & When compromise is needed \\
\hline Reciprocals & $\begin{array}{l}\text { If activity } i \text { has one of the above } \\
\text { numbers assigned to it when compared } \\
\text { with activity } j \text {, then } j \text { has the reciprocal } \\
\text { values when compared with } i\end{array}$ & $\begin{array}{l}\text { Essentially opposing. If one value is } 9 \text {, } \\
\text { then the reciprocal is } 1 / 9\end{array}$ \\
\hline Rationales & Ratios arising from the scale & $\begin{array}{l}\text { If consistency were to be forced by } \\
\text { obtaining } n \text { numerical values to span } \\
\text { the matrix }\end{array}$ \\
\hline
\end{tabular}

In order to collect this information clearly and efficiently, a 'researcher-administered' survey interview was conducted as part of a group exercise, utilising digital communications technology with the ability to record the session (Microsoft Teams). Further, each participant as part of the focus group, was asked to rate or prioritise the relevance of one criteria over another, and then the same for each alternative with agreements made in the workshop of the collective values in the spirit of collaboration. Following this data attainment, the AHP matrix values were actively populated by the interviewer as the interview progressed. The methodology and format of the structure of how these relevant placeholder fields (focus, criteria and alternatives) and also eigenvalues (weighted prioritised values) are captured within the matrix is outlined in detail within the next section.

\subsubsection{Pairwise Structure and Development}

As part of the sample group focused interview in determining collaborative BIM prioritisations and relevance factors, a $5 \times 5$ matrix was developed to facilitate the capture of the assigned eigenvalues (fundamental scales) which formed part of the assessment criteria, alternative and weightings. Collectively as part of a pre-arranged interview participants applied their collective valuations after debating topics between each other their combined ranking of criterion $\left(\mathrm{C}^{\mathrm{n}}\right)$ and or Alternatives $\left(\mathrm{A}^{\mathrm{n}}\right)$.

Furthermore, for each criteria developed, the subsequent alternatives were then cross-compared and weighted fundamental scales applied (prioritisation of one power over another) which was identical to the assignment of values for criteria beforehand, to ascertain the more dominant element and thus a multiplier required for synthesising valuations. Table 8 below shows the template matrix at the data collection stage for each criterion versus the alternative measures. 
Table 8. Criteria versus alternatives

\begin{tabular}{|c|c|c|c|c|c|}
\hline Focus Area & & & & & \\
\hline Criteria ' $n$ ' & Alternative ${ }^{1}$ & Alternative ${ }^{2}$ & Alternative $^{3}$ & Alternative ${ }^{4}$ & Alternative $^{5}$ \\
\hline Alternative $^{1}$ & DO NOT FILL & \multirow{2}{*}{ DO NOT FILL } & \multirow{3}{*}{ DO NOT FILL } & \multirow{4}{*}{ DO NOT FILL } & \multirow{5}{*}{ DO NOT FILL } \\
\hline Alternative $^{2}$ & Required & & & & \\
\hline Alternative $^{3}$ & Required & Required & & & \\
\hline Alternative $^{4}$ & Required & Required & Required & & \\
\hline Alternative $^{5}$ & Required & Required & Required & Required & \\
\hline
\end{tabular}

The section which follows provides a breakdown of the data collected from each participant and then group activities for parts 1 and 2, along with the produced synthesised findings through the consolidation of matrices.

\subsection{Results}

This section evidences the findings attained from each individual participant (15 in total split equally across academic, design and construction environments) through the electronic survey data capture technique. The findings were then consolidated and rationalised based on the most common and linked items to form the five criteria and five alternatives undertaken by the focus group, which complement the goal (pre-determined as collaborative BIM), for population into the pairwise AHP matrix. Further to determining the criteria and alternatives, each participant was asked to comment on the current methodologies for measuring these elements, as well as a proposal for an alternative measurement technique.

\subsubsection{Part One- Data Collection- Criteria and Alternatives Development}

Data received from the 15 participants in order to outline and capture participants inputs in developing the criteria and alternatives in sight of the pre-determined goal/objective of collaborative BIM was achieved through the utilisation of the Microsoft Forms online platform. Further, a unification of the most common areas defined is presented within Figure 7, which is used in part 2 to appropriately weight the importance values (ranking) of the developed criteria and alternatives within the $5 \times 5$ pairwise matrix.

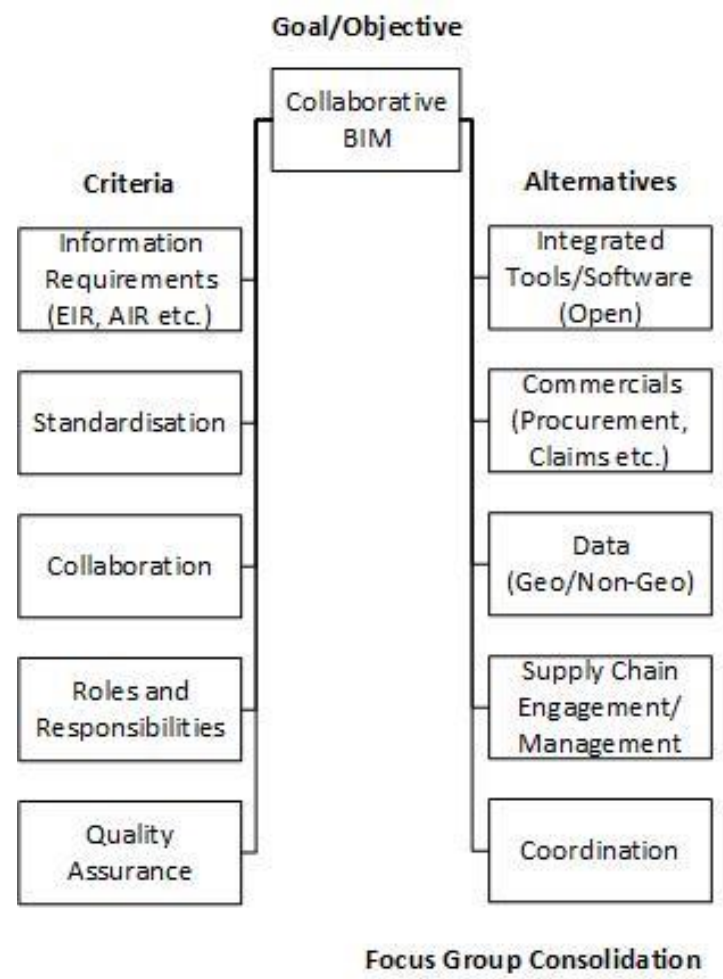

FIG. 7: Unified focus group criteria and alternative data consolidation 
A rationalisation exercise was undertaken to consolidate and unify the participants individuals answers into a singular understanding of the criteria and alternatives. This was in order to determine the core underpinning elements of Collaborative BIM on the hypothetical infrastructure project as a baseline for Part 2.

Transferring the unified criteria and alternatives into a hierarchical structured network (namely AHP network), Figure 8 below shows the interconnections with focus to the ultimate predetermined goal/objective including the determined criteria and alternatives agreed by the participants as part of the data collection exercise (survey).

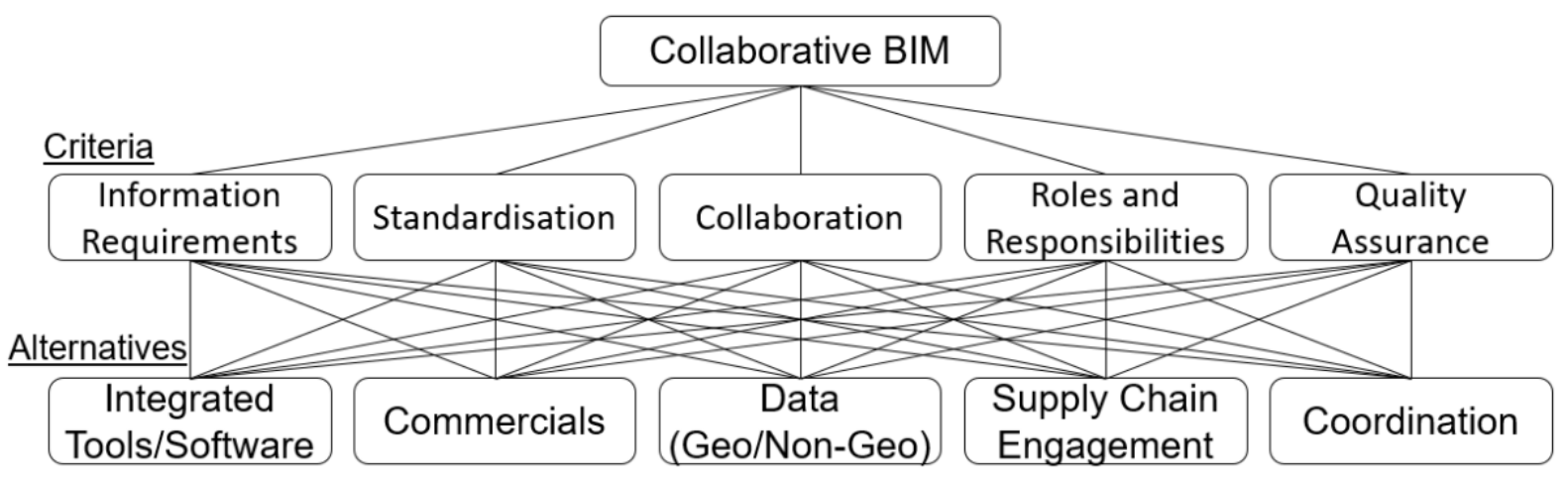

FIG. 8: Populated AHP network, post data collection (consolidation)

\subsubsection{Part Two- Data Collection- Pairwise Matrix Importance Values}

The second stage of the data collection process involved undertaking an online focus group interview whereby each participant collectively agreed, as part of the collaborative BIM hypothetical infrastructure project, the fundamental scales (importance priority factors) for the criteria and alternatives in respect to the adapted AHP network structure.

To add further transparency of the findings collected as part of the second phase of data collection (focus group interview), a synthesised and globalised matrix has been produced as shown below in Table 9 to outline firstly the criteria which is most dominant when focusing on collaborative BIM, as well as outlining the ranking of each of the criteria and their corresponding alternatives. This latter item is provided within an idealised alternatives column, which shows the dominance of the alternative in respect to the associated criteria and their importance in respect to achieving the upstream criterion.

The synthesised findings within Table 9 below show that 'Information Requirements' are the dominantly weighted (globalised ranking $1^{\text {st }}$ ), and thus most highly ranked prioritisation in respect to achieving collaborative BIM, supported by the integration of Data (Geometric/Non-Geometric). These prioritisations throughout this comparative visualisation were determined through the application of the fundamental scaling (see table 7 above) through the adaption of the Analytical Hierarchy Process (AHP) by the focus group participants and rely of consistency indexing and ratios to validate that the inputs and derived outcomes fall within the hierarchical networks permissible scales.

Table 9. Synthesised global findings

\begin{tabular}{|c|c|c|c|c|c|c|}
\hline Criteria & Alternatives & $\begin{array}{c}\text { L1 } \\
\text { CRIT. } \\
\text { Priority }\end{array}$ & $\begin{array}{l}\text { L2 ALT. } \\
\text { Priority }\end{array}$ & $\begin{array}{l}\text { Global Weight } \\
\text { (Criteria x } \\
\text { Alternatives) } \\
\end{array}$ & $\begin{array}{c}\text { Idealised } \\
\text { Alternatives }\end{array}$ & $\begin{array}{c}\text { Globalised } \\
\text { Ranking } \\
\text { Criteria } \\
\end{array}$ \\
\hline \multirow{6}{*}{ 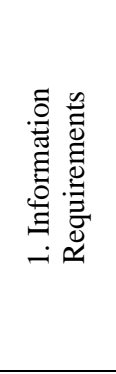 } & 1. Integrated Tools/Software (Open) & \multirow[t]{5}{*}{0.582} & 0.03 & $1.87 \%$ & $6.41 \%$ & \multirow[t]{6}{*}{$1 \mathrm{st}$} \\
\hline & 2. Commercials & & 0.07 & $4.16 \%$ & $14.26 \%$ & \\
\hline & 3. Data (Geometric/Non-Geometric) & & 0.50 & $29.19 \%$ & $100.00 \%$ & \\
\hline & \begin{tabular}{|lcc}
4. & Supply & Chain \\
Engagement/Management & \\
\end{tabular} & & 0.09 & $5.17 \%$ & $17.73 \%$ & \\
\hline & 5. Model Coordination & & 0.31 & $17.83 \%$ & $61.09 \%$ & \\
\hline & & Total & 1.00 & $58.23 \%$ & & \\
\hline
\end{tabular}




\begin{tabular}{|c|c|c|c|c|c|c|}
\hline Criteria & Alternatives & $\begin{array}{c}\text { L1 } \\
\text { CRIT. } \\
\text { Priority } \\
\end{array}$ & $\begin{array}{l}\text { L2 ALT. } \\
\text { Priority }\end{array}$ & $\begin{array}{l}\text { Global Weight } \\
\text { (Criteria x } \\
\text { Alternatives) } \\
\end{array}$ & $\begin{array}{c}\text { Idealised } \\
\text { Alternatives }\end{array}$ & $\begin{array}{c}\text { Globalised } \\
\text { Ranking } \\
\text { Criteria } \\
\end{array}$ \\
\hline \multirow{6}{*}{ 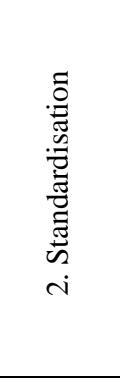 } & 1. Integrated Tools/Software (Open) & \multirow[t]{5}{*}{0.051} & 0.08 & $0.42 \%$ & $15.44 \%$ & \multirow[t]{6}{*}{5 th } \\
\hline & 2. Commercials & & 0.10 & $0.52 \%$ & $18.99 \%$ & \\
\hline & 3. Data (Geometric/Non-Geometric) & & 0.54 & $2.72 \%$ & $100.00 \%$ & \\
\hline & \begin{tabular}{|lcc} 
4. Supply & Chain \\
Engagement/Management & \\
\end{tabular} & & 0.14 & $0.69 \%$ & $25.30 \%$ & \\
\hline & $\begin{array}{l}\text { Engagement/Management } \\
\text { 5. Model Coordination } \\
\end{array}$ & & 0.14 & $0.73 \%$ & $26.89 \%$ & \\
\hline & & Total & 1.00 & $5.08 \%$ & & \\
\hline \multirow{6}{*}{ 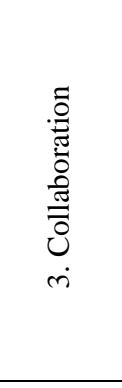 } & 1. Integrated Tools/Software (Open) & \multirow[t]{5}{*}{0.071} & 0.12 & $0.82 \%$ & $32.92 \%$ & \multirow[t]{6}{*}{4 th } \\
\hline & 2. Commercials & & 0.06 & $0.42 \%$ & $16.88 \%$ & \\
\hline & 3. Data (Geometric/Non-Geometric) & & 0.35 & $2.44 \%$ & $100.00 \%$ & \\
\hline & \begin{tabular}{|lcc} 
4. Supply & Chain \\
Engagement/Management & \\
\end{tabular} & & 0.13 & $0.89 \%$ & $35.55 \%$ & \\
\hline & 5. Model Coordination & & 0.35 & $2.50 \%$ & $100.00 \%$ & \\
\hline & & Total & 1.00 & $7.07 \%$ & & \\
\hline \multirow{6}{*}{ 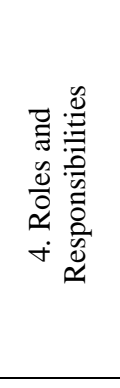 } & 1. Integrated Tools/Software (Open) & \multirow[t]{5}{*}{0.099} & 0.05 & $0.52 \%$ & $11.69 \%$ & \multirow[t]{6}{*}{$3 \mathrm{rd}$} \\
\hline & 2. Commercials & & 0.45 & $4.47 \%$ & $100.00 \%$ & \\
\hline & 3. Data (Geometric/Non-Geometric) & & 0.05 & $0.52 \%$ & $11.69 \%$ & \\
\hline & \begin{tabular}{|lcc} 
4. Supply & Chain \\
Engagement/Management & \\
\end{tabular} & & 0.39 & $3.85 \%$ & $86.04 \%$ & \\
\hline & 5. Model Coordination & & 0.05 & $0.52 \%$ & $11.69 \%$ & \\
\hline & & Total & 1.00 & $9.89 \%$ & & \\
\hline \multirow{6}{*}{ 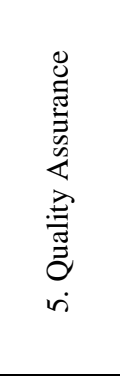 } & 1. Integrated Tools/Software (Open) & \multirow[t]{5}{*}{0.197} & 0.04 & $0.82 \%$ & $11.34 \%$ & \multirow[t]{6}{*}{ 2nd } \\
\hline & 2. Commercials & & 0.19 & $3.77 \%$ & $51.99 \%$ & \\
\hline & 3. Data (Geometric/Non-Geometric) & & 0.18 & $3.64 \%$ & $50.21 \%$ & \\
\hline & \begin{tabular}{|lcc} 
4. Supply & Chain \\
Engagement/Management & \\
\end{tabular} & & 0.37 & $7.26 \%$ & $100.00 \%$ & \\
\hline & 5. Model Coordination & & 0.21 & $4.23 \%$ & $58.29 \%$ & \\
\hline & & Total & 1.00 & $19.73 \%$ & & \\
\hline & & & Total & $100.00 \%$ & & \\
\hline
\end{tabular}

\section{ANALYSIS}

This section analyses the data collected through the survey methodology of parts one; a semi-structured survey questionnaire, and two; a focus group interview determining the priority ranking of the former defined items. A summary through cross analysis provides further descriptive reasoning to the evidence and thus findings from the data provided, as part of the hypothetical infrastructure project.

\subsection{Part One Analysis}

Data was individually collected from participants as part of the self-administered technique (questionnaire) to determine what the criteria and alternatives were in support of achieving collaborative BIM . However, and before this, a syntax was developed for the specific project to remove the barrier of what BIM means for the hypothetical project, to determine with clarity what the position of BIM is for the project and to prepare participants in 
developing what the main constituent parts of BIM are. This effectively directed participants in a unified manner, reducing the potential of a mass amount of varying data and opinions due to disconnect of the definition of BIM for the project. Further, as they were totally isolated in sharing their thoughts on what the criteria (first level of what BIM is supported by i.e., standards) and alternatives (second level of what BIM is supported by i.e., coordination) are through the use of an online survey, validation that the syntax has benefit was gathered as there were commonalities in the core findings at this stage of the data collection process. Typical and again common findings were apparent through dominated repetition within five areas of criteria and five areas of alternatives respectively. Moreover, of the 15 participants interviewed which were equally split across academia and industry (design and construction), mutual themes were evidenced throughout as being important to the success of collaborative BIM including standardisation, collaboration, coordination, information, open source, commercials, integration and procurement respectively.

Table 10 below confirms this rationalised data, where the authors analysed the dataset of 150 inputs and consolidated these into 10 (five criteria and five alternatives) of the most common areas of importance, which is the structure for the part two exercise. This evidence shows the most important factors when focusing on collaborative BIM (level 1), with sub-elements (level 2) supporting the delivery of the former items.

Table 10. Consolidated dataset for importance factors in delivering collaborative BIM

\begin{tabular}{|l|l|}
\hline Criteria (level 1) & Alternatives (level 2) \\
\hline Information requirements & Integrated tools/software (open) \\
\hline Standardisation & Commercials \\
\hline Collaboration & Data (geometric and non-geometric) \\
\hline Roles and responsibilities & Supply chain engagement/management \\
\hline Quality assurance & Model coordination \\
\hline
\end{tabular}

A point to note is that due to the detailed descriptive nature of the thematic and qualitative feedback received from participants at the survey stage, the authors grouped some of the answers into the most relevant data headers above e.g., if cost analysis at the bid stage was provided, this fits within the commercials items.

\subsection{Part Two Analysis}

Next and building upon part one, prioritised weighting/rankings were assigned to each of the criteria and alternatives through the utilisation of the research administered technique in respect to how important each element was, in order to achieve either collaborative BIM or in order to achieve each of the criteria. This is of course in respect to the ultimate objective being to achieve collaborative BIM on a hypothetical infrastructure project.

Upon review of the main blockers and thus inefficiencies as evidenced through exploration of the literature and data collection from industry experts towards achieving collaborative BIM, standards and quality assurance were rated as inconsistent. This is in terms of evidence provided stating the sheer amount, along with the complexity in wording forms a basis of how unlikely they are to be applied practically from the textbook. Through analysis of the pairwise methodology developed as part of this study and despite a range of standards, guidance documents, delivery frameworks and commercial procurement routes, inconsistencies are validated further again within the measurement framework as part of this study which is evidenced below in Table 11. This table clarifies and further represents the consistency factor ratings deduced from the data collection exercise, in part through the use of the AHP matrix network.

Table 11. Summary of consistency ratings in light of findings

\begin{tabular}{|l|l|l|}
\hline Criteria & Percentage of importance (\%) & Consistent <10\%) or Inconsistent (>10\%) \\
\hline Information requirements & 7.2 & Consistent \\
\hline Standardisation & 54.9 & Inconsistent \\
\hline Collaboration & 4.9 & Consistent \\
\hline Roles and responsibilities & 0.2 & Consistent \\
\hline Quality assurance & 11.5 & Inconsistent \\
\hline
\end{tabular}


In spite of these inconsistent findings, participants stated that the developed methodology they were using as part of this survey and focus group exercise was the first time a truly collaborative weighting of collaborative BIM, supported with and by developed descriptors, had been undertaken and utilised before the project is expected to be delivering outputs. Furthermore, this reaffirms evidenced collected at the literature review and survey stages respective in that BIM is inherently inconsistent in how it is applied which is evidenced within the data and AHP consistency ration for both standardisation and quality assurance, despite having an existing developed and measurable framework for the execution of BIM (ISO19650 and formerly BS/PAS1192).

Analysing the data collected further, with collaborative BIM being the ultimate objective for the hypothetical infrastructure project including a diverse range of participants across academia, construction and design all with a bias and expertise within the BIM environment. From this data provided in the form of weighted rankings collectively by the focus group, information requirements were ranked and prioritised highest collectively facilitated by the developed model to be $58.2 \%$ dominant over the other criteria. Moreover, and for clarity, this is in respect to the importance of being able to achieve collaborative BIM. Furthermore, and with this in sight, the next and nearest weighting for importance factor was quality assurance at $19.7 \%$, which is almost $40 \%$ less of a priority than information requirements, in order to achieve collaborative BIM. This means that participants valued having the information requirements i.e., how and what to deliver at which timescales across the project lifecycle, as being most important in respect to the other criteria.

Figure 9 below outlines these findings visually and comparatively in a scatter graph format.

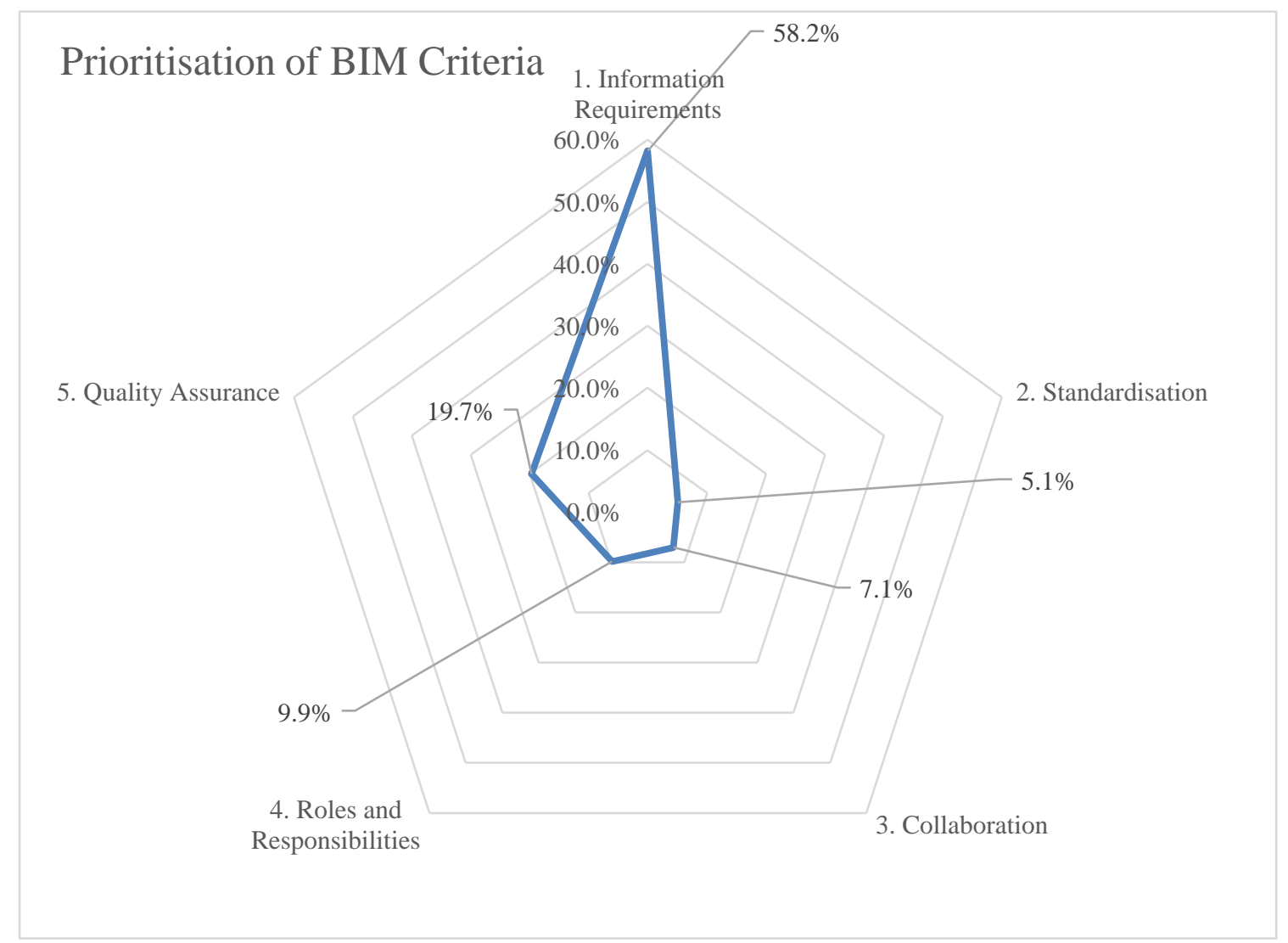

FIG. 9: Scatter graph of prioritised weighting (towards collaborative BIM (objective))

Additionally, and in terms of the supportive alternatives which support the understanding and ultimately the delivery of this core item, data (geometric and non-geometric) was assigned the highest sub-weighting directly in relation to information requirements, which was followed closely by model coordination. 


\section{RESEARCH CONTRIBUTIONS AND LIMITATIONS}

The research undertaken as part of this study contributes to the field of collaborative BIM through novel research founded on exploring the current theoretical and practical environment alongside the implementation practices and measurement methodologies. Further, inclusion of underpinning literature from both academic and industry literature is explored as well as focus group surveys with BIM experts from academia, design and construction sectors respectively. A unified and agreed approach outlining the aspiration and objectives of and for collaborative BIM at a working level, including the fundamental explanatory parts, their ranking (prioritisation) and thusly where their focus should be in order to achieve the initial goal is beneficial in reducing the barriers of collaborative BIM. Three core elements underpinning collaborative BIM as part of the data collection/focus group case study was built upon developing a unique syntax of what the context of BIM is, to which the prioritised elements which were outputted from the developed alternative implementation model were in order of priority information requirements $(58.2 \%)$, quality assurance $(19.7 \%)$ and roles and responsibilities $(9.9 \%)$. Moreover, the pairwise based implementation matrix enables the conversion of qualitative spoken inputs (objective, criteria and alternatives) and their assignment in a quantifiable number (prioritised rankings), which enables a more analytical and measured approach to defining the weightings, risk(s) and key areas of focus to enable the likelihood of achieving the outcomes and thus benefits of BIM, across all stages of the project lifecycle. The developed approach model is novel and to date has not been focused by others on the inefficiencies and objectives, leading towards an alternative solution to induce clarity and ultimately bettering implementation. Limitations and restrictors as part of this research were that the methodology requires multiple stakeholders to define their objective(s)/focus and actively work in a collaborative manner with their team members/stakeholders from the beginning, to gain the most from the methodology. Also, inclusion a wider focus group of Collaborative BIM would be beneficial to focus on a more diverse range of industry experts, to compliment and support the academia case studies

\section{CONCLUSIONS}

In conclusion to this research study, several key objectives as outlined in section 3 were defined and achieved in order to create a unified and agreed approach outlining the aspiration and objectives of and for collaborative BIM at a working level(objective 1 and 2), including the fundamental explanatory parts, their ranking (prioritisation) (objective 3) and thusly where their focus should be in order to achieve the initial goal is novel and beneficial in reducing the barriers of collaborative BIM. Further, this newly developed and validated objective focused methodology utilising the AHP pairwise methodology gives stakeholders a clearer, unified way of outlining objectives not solely in terms of what the ultimate goal is, but by developing and then prioritizing core agreed elements in order to increase the likelihood of successful collaborative BIM understanding and delivery thereof (objective 4). Applying qualitative to quantitative reasoning enables the reduction of spikes in opinions, inconsistencies and also consistencies becoming transparent and mirroring/revealing theoretical underpinnings and practical revelations (objective 5), as well as a lessening in confusion through mathematically measurable clarity and assurance in order to achieve collaborative BIM not just at the start of projects but through their lifecycle (through reassessment). Furthermore, by agreeing and capturing at the outset what a project wants to achieve via BIM (objective) and then progressing to agreeing what the main parts are of this requirement are (criteria and alternatives) and what people we have to do to achieve these outcomes, creates a truly understood collaborative team and thus singular approach to implementing and executing collaborative BIM (objective 6).

\section{FUTURE WORKS}

Future works may include additional applied use cases of the developed implementation measurement methodology across a broad range of BIM projects, which can be utilised to improve adoption and also validate and improve the likelihood of successfully delivering BIM across a range of sectors. Further, the development of a robust and complimentary measurement system specifically towards providing clarity on where the progress is and where it should be in light of the prioritised globalised rankings to achieve specific BIM outcomes would be beneficial. Additional exploration and expansion of the current measurement systems appear to be beneficial due to evidence suggesting they are not fully defined, widely understood and/or applied or utilised at the active delivery cycle stage of projects. This future research could also benefit from the continuation and inclusion of academic, design and construction BIM biased experts as per the schema of the findings within as utilised through this research study. 


\section{ACKNOWLEDGMENTS}

The authors would like to thank the focus group participants who provided key input to the data collection exercise as part of this research study from across academia, design and construction.

\section{REFERENCES}

Attride-Stirling, J. (2001), Thematic networks: An analytic tool for qualitative research, Qualitative Research, 1, 385-405. doi:10.1177/146879410100100307

Akponeware, Anderson \& Adamu, Zulfikar. (2017), Clash Detection or Clash Avoidance? An Investigation into Coordination Problems in 3D BIM. Buildings. 7. 75-103. 10.3390/buildings7030075.

K.M.A. Al-Harbi (2001), Application of the AHP in project management, Int. J. Proj. Manag. 19 (2001) 19-27.

Aljumaiah, B (2020), Building Information Modelling to City Information Modelling (BIM to CIM), Eastern Province Municipality, Saudi Arabia

Aouad, G., Cooper, R., Fu, C., Lee, A., Ponting, A., Tah, J., and Wu, S., (2005), “nD Modelling - a driver or enabler for construction improvement", RICS Research paper series, Volume 5, number 6.

Y. Arayici, P. Coates, L. Koskela, M. Kagioglou, C. Usher, K. O'Reilly (2011), Technology adoption in the BIM implementation for lean architectural practice, Autom. Constr. 20 (2) (March 2011) 189-195.

S. Azhar, M. Khalfan, T. Maqsood (2012), Building information modelling (BIM): now and beyond, Australas. J. Constr. Econ. Build. 12 (4) (2012) 15-28.

Bargstädt, H.J, (2015), Challenges of BIM for Construction Site Operations, Procedia Engineering, Volume 117, 2015, Pages 52-59, ISSN 1877-7058, https://doi.org/10.1016/j.proeng.2015.08.123.

Barlish, K. and Sullivan, K., (2012), How to Measure the Benefits of BIM - A case study approach. Automation in Construction, 24(1), 149-159.

Baxter, P., \& Jack, S. (2008). Qualitative Case Study Methodology: Study Design and Implementation for Novice Researchers. The Qualitative Report, 13(4), 544-556.

Belton, V., \& Stewart, T. (2002), Multiple criteria decision analysis: An integrated approach. Boston, MA: Kluwer Academic Publishers

R. Benayoun, B. Roy, B. Sussman (1966), ELECTRE: Une m’ethode pour guider le choix en pr'esence de points de vue multiples, Note de travail 49, 1966.

Bew, M., Underwood, J., Wix, J., \& Storer, G. (2008). Going BIM in a commercial world. Paper presented at the EWork and EBusiness in Architecture, Engineering and Construction: European Conferences on Product and Process Modeling (ECCPM 2008), Sophia Antipolis, France.

Bond, S.D., Carlson, K.A., et al (2008), Generating objectives: can decision makers articulate what they want? Management Science, 54(1), 56--70 (2008)

Borenstein M., Hedges L., Higgins J., Rothstein H (2009), Introduction to meta-analysis. Hoboken, nj: John Wiley \& Sons Inc; 2009.

Braun, V., Clarke, V. (2006), Using thematic analysis in psychology, Qualitative Research in Psychology, 3, 77101. doi:10.1191/1478088706qp063oa

N. Bryson, and A. Mobolurin (1995), An action learning evaluation procedure for multiple criteria decision making problems, European Journal of Operational Research, Vol. 96, 1995, pp. 379-386.

BSI (2013), PAS1192-2:2013, https://shop.bsigroup.com/en/Sandpit/PAS-old-forms/PAS-1192-2/Confirmation/ (accessed 03 August 2021)

BSI (2018), BS EN ISO19650-2:2018+Revision, https://shop.bsigroup.com/ProductDetail/?pid=000000000030420198 (accessed 03 August 2021) 
Fulvio Re Cecconi, Lavinia C. Tagliabue, Sebastiano Maltese, Martina Zuccaro (2017), A Multi-criteria Framework for Decision Process in Retrofit Optioneering through Interactive Data Flow, Procedia Engineering, Volume 180, 2017, Pages 859-869, ISSN 1877-7058, https://doi.org/10.1016/j.proeng.2017.04.247.

Racha Chahrour, Mian Atif Hafeez, Ahmad Mohammad Ahmad, Hashim Ibnauf Sulieman, Huda Dawood, Sergio Rodriguez-Trejo, Mohamad Kassem, Khalid Kamal Naji \& Nashwan Dawood (2021), Costbenefit analysis of BIM-enabled design clash detection and resolution, Construction Management and Economics, 39:1, 55-72, DOI: 10.1080/01446193.2020.1802768

Chan, A.P., and Chan, A.P. (2004), "Key performance indicators for measuring construction success." Benchmarking, 11(2), 203-221.

P. Chinowsky and E. Rojas (2003), "Virtual Teams: Guide to Successful Implementation,” J. Manag. Eng., vol. 19, no. 3, pp. 98-106.

J. Chou (2008), Applying AHP-based CBR to estimate pavement maintenance cost, Tsinghua Sci. Technol. 13 (Supplement 1) (2008) 114-120.

Construction Innovation Hub (2020), Driving transformation, delivering value: Output from Government Discovery research, https://constructioninnovationhub.org.uk/wpcontent/uploads/2020/07/FINAL_GovernmentDiscover_Report.pdf (accessed 18 August 2021).

R.F. Cox, R.R.A. Issa, D. Ahrens (2003), Management's perception of key performance indicators for construction, Journal of Construction Engineering and Management 142-151.

Da Silva, Paula \& Crippa, Julianna \& Scheer, Sergio. (2019), BIM 4D in Construction Scheduling: Details, Benefits and Difficulties. 10. 19010. 10.20396/parc.v10i0.8650258.

De Vaus, D. A. (2002), Surveys in social research: Taylor \& Francis.

DiCicco-Bloom, Barbara \& Crabtree, Benjamin. (2006), The qualitative research interview, Medical education, 40. 314-21. 10.1111/j.1365-2929.2006.02418.x.

Doran, G. T. (1981), There's a S.M.A.R.T. Way to Write Management's Goals and Objectives. Management Review, 70, 35-36.

Dossick, Carrie. (2015), Learning in Global Teams: BIM Planning and Coordination. International Journal of Automation and Smart Technology. 5. 119-135. 10.5875/ausmt.v5i3.916.

Eadie, Robert \& Browne, Mike \& Odeyinka, Henry \& Mckeown, Clare \& McNiff, Sean (2013), BIM implementation throughout the UK construction project lifecycle: An analysis, Automation in Construction. 36. 145-151. 10.1016/j.autcon.2013.09.001.

C Eastman, P Teicholtz, R Sacks and K Liston (2011), BIM Handbook: A Guide to Building Information Modeling for Owners, Managers, Designers, Engineers and Contractors, Second Edition, USA.

M. Ei-Mikawi, A.S. Mosallam (1996), A methodology for evaluation of the use of advanced composites in structural civil engineering applications, Compos. Part B 27 (1996) 203-215.

Ellis, H.M. (1970), The Application of Decision Analysis to the Problem of Choosing an Air Pollution Control Program for New York City. Unpublished Ph.D. dissertation, Graduate School of Business Administration, Harvard University, Cambridge, Mass., 1970.

Eppler, M.J., \& Platts, K.W. (2009), Visual strategizing: The systematic use of visualization in the strategicplanning process, Long Range Planning, 42, 42-74.

Daniel Jato-Espino, Elena Castillo-Lopez, Jorge Rodriguez-Hernandez, Juan Carlos Canteras-Jordana (2014), A review of application of multi-criteria decision making methods in construction, Automation in Construction, Volume 45, 2014, Pages 151-162, ISSN 0926-5805, https://doi.org/10.1016/j.autcon.2014.05.013. 
Farmer (2016), The Farmer Review of UK Construction Labour Model, https://www.constructionleadershipcouncil.co.uk/wp-content/uploads/2016/10/Farmer-Review.pdf (accessed 03 August 2021).

Felix, R (2015), On Consistency of Decision Goals and Separability of Preferences of Decision Alternatives, 2015 Conference of the International Fuzzy Systems Association and the European Society for Fuzzy Logic and Technology (IFSA-EUSFLAT-15).

Foddy, W.H. (1994), Constructing Questions for Interviews and Questionnaires: Theory and Practice in Social Research. New Edition, Cambridge University Press, Cambridge, UK.

Fortune, C. (2006), "Process standardization and the impact of professional judgement on the formulation of building project budget price advice.", Constr. Manage. Econ., 24(10), 1091-1098.

N.D. Gil, I.D. Tommelein, A. Stout, T. Garrett (2005), Embodying product and process flexibility to cope with challenging project deliveries, Journal of Construction Engineering and Management (2005) 439-448.

Glaser, B., \& Strauss, A. (1967), The Discovery of Grounded Theory: Strategies for Qualitative Research. Mill Valley, CA: Sociology Press

Govindan, K. Jepsen, M.B, (2016), ELECTRE: A comprehensive literature review on methodologies and applications, European Journal of Operational Research, 2016, vol. 250, issue 1, 1-29

Green, J. (2000) Understanding social programs through evaluation. In Denzin, N., Lincoln, Y. (Eds.), Handbook of qualitative research (2nd ed., pp. 981-999). London, England: Sage.

Gregory, R., Failing, L., Harstone, M., Long, G., McDaniels, T. \& Ohlson, D.(2012), Structured Decision Making: A Practical Guide to Environmental Management Choices. Wiley-Blackwell, Oxford, UK. (PDF) Predicting species distributions for conservation decisions.

Guðlaugsson B., Fazeli R., Gunnarsdóttir I., Davidsdottir B., Stefansson G., (2020), Classification of stakeholders of sustainable energy development in Iceland: Utilizing a power-interest matrix and fuzzy logic theory, Energy for Sustainable Development, Volume 57, 2020, Pages 168-188, ISSN 0973-0826, https://doi.org/10.1016/j.esd.2020.06.006

Hart, C. (2001), Doing a literature search. London: Sage

D. Holzer (2007), Are you talking to me? Why BIM alone is not the answer, Association of Architecture Schools in Australasia

A. Hore, R. Montague, K. Thomas, F. Cullen (2011), Advancing the use of BIMthrough a government funded construction industry competency centre in Ireland, CIB W78 2011: 28th International Conference, Paris, 26-28 October 2011, 2011.

Doloi, Hemanta. (2013), Cost Overruns and Failure in Project Management: Understanding the Roles of Key Stakeholders in Construction Projects. Journal of Construction Engineering and Management. 139. 267279. 10.1061/(ASCE)CO.1943-7862.0000621.

HM Government (2011), Prime Ministers Mandate for the Major Projects Authority, https://assets.publishing.service.gov.uk/government/uploads/system/uploads/attachment_data/file/37850 9/PM_mandate_for_MPA_2011.pdf (accessed 18/08/2021)

HMSO (2016), Government construction strategy: 2016-2020, London, UK, 2016.

S. Hughes (2017), Moving to industry 4.0: A skills revolution, Mace Group Ltd., London, UK, 2017.

W. Ibbs, L.D. Nguyen, L. Seulkee (2007), Quantified impacts of project change, Journal of Professional Issues in Engineering Education and Practice (2007) 45-52.

ICE (2015), Performance improvement in Area 13 of the Highways England network, https://www.ice.org.uk/knowledge-and-resources/case-studies/performance-improvement-area-13 (accessed 03 August 2021) 
Indiana University (2009), IU BIM Guidelines and Standards, https://knowledge.autodesk.com/akn-aknsitearticle-attachments/8a7f652b-edb7-4fb4-87a2-2eaec27ec6cc.pdf

Indiana University. (2012). IU BIM Proficiency Matrix. [www Document]. URL http://www.indiana.edu/ uao/docs/standards/IU\%20BIM\%20Proficiency\%20Matrix.xls

Infrastructure and Projects Authority (IPA) (2016), 'Guidance for Departments and review teams. Assurance of Benefits Realisation in Major Projects. Supplementary Guidance v1, available at: https://www.gov.uk/government/publications/major-projects-authority-assurance-toolkit

Infrastructure and Projects Authority (2017), “Transforming infrastructure performance,” HMSO, London, UK, 2017.

Infrastructure and Projects Authority (IPA) (2021), Mandate, https://assets.publishing.service.gov.uk/government/uploads/system/uploads/attachment_data/file/94986 8/IPA_Mandate_2021.pdf (accessed 03 August 2021)

Ishizaka, Alessio \& Siraj, Sajid. (2017), Are multi-criteria decision-making tools useful? An experimental comparative study of three methods. European Journal of Operational Research. 264. 10.1016/j.ejor.2017.05.041.

E. Jalilzadehazhari, P. Johansson (2019), Integrating BIM, Optimization and a Multi- Criteria Decision-Making Method in Building Design Process, Springer, Advances in Informatics and Computing in Civil and Construction Engineering, 2019, pp. 359-369.

Jato-Espino et al., (2014), A review of application of multi-criteria decision-making methods in construction

Jordani, D. (2008), BIM: A Healthy Disruption to a Fragmented and Broken Process, Journal of Building Information Modelling, Spring 2008, 24-26.

G, Kabir, R, Sadiq and S, Tesfamariam (2014), A review of multi-criteria decision-making methods for infrastructure management, Structure and Infrastructure Engineering: Maintenance, Management, LifeCycleDesign and Performance, 10:9, 1176-1210, DOI: 10.1080/15732479.2013.795978

M. Kagioglou, R. Cooper, G. Aouad (2001), Performance management in construction: a conceptual framework, Constr. Manag. Econ. 19 (1) (January 1 2001) 85-95.

Keeney (1974), Multiplicative utility functions, Oper. Res., 22 (1974), pp. 22-34

R. L. Keeney and H. Raiffa (1976), Decisions with Multiple Objectives: Preferences and Value Trade-Offs(New York: Wiley)

Kiker, G.A., Bridges, T.S., Varghese, A., Seager, P.T., \& Linkov, I. (2005), Application of multicriteria decision analysis in environmental decision making. Integrated Environmental Assessment and Management, $1(2), 95-108$

Y. Lai, W. Wang, H. Wang (2008), AHP- and simulation-based budget determination procedure for public building construction projects, Autom. Constr. 17 (2008) 623-632.

C. Lin, W. Wang, W. Yu (2008), Improving AHP for construction with an adaptive AHP approach (A3), Autom. Constr. 17 (2008) 180-187.

Matteo (2015), Introduction to the Analytic Hierarchy Process

Lockamy III, A., \& McCormack, K. (2004). The development of a supply chain management process maturity model using the concepts of business process orientation. Supply Chain Management: An International Journal, 9(4), 272-278.

Macharis, C., Verbeke, A., De Brucker, K., (2004), The strategic evaluation of new technologies through multicriteria analysis: the Advisors case, Research in Transportation Economics, 8, 443-462.

Marttunen, Mika \& Mustajoki, Jyri \& Dufva, Mikko \& Karjalainen, Timo. (2015), How to design and realize participation of stakeholders in MCDA processes? A framework for selecting an appropriate approach. EURO Journal on Decision Processes. 3. 187-214. 10.1007/s40070-013-0016-3. 
M. Marzouk (2010), An application of ELECTRE III to contractor selection, Construction Research Congress, 2010, pp. 1316-1324.

McKinsey (2020), How Disruption is Reshaping Construction, https://www.mckinsey.com/businessfunctions/operations/our-insights/the-next-normal-in-construction-how-disruption-is-reshaping-theworlds-largest-ecosystem (accessed 18-08-21)

Mulvihill, John \& Brenner, Everett. (1968), Ranking boolean search output, American Documentation 19. 204205, 10.1002/asi.5090190217.

Munda, Giuseppe. (2004), Munda, G.: Social Multi-Criteria Evaluation: Methodological Foundations and Operational Consequences. European Journal of Operational Research 158(3), 662-677. European Journal of Operational Research. 662-677. 10.1016/S0377-2217(03)00369-2.

NBIMS (2007), Proforma for I-CMM, http://www.facilityinformationcouncil.org/bim/pdfs/BIM_CMM_v1.8.xls (accessed 01 August 2021)

Nightingale, D.J., \& Mize, J.H. (2002). Development of a lean enterprise transformation maturity model. Information Knowledge Systems Management, 3(1), 15-30.

Nowell LS, Norris JM, White DE, Moules NJ. (2017), Thematic Analysis: Striving to Meet the Trustworthiness Criteria. International Journal of Qualitative Methods. December 2017. doi:10.1177/1609406917733847

Ollerenshaw, A., Aidman, E., \& Kidd, G. (1997). Is an illustration always worth ten thousand words? Effects of prior knowledge, learning style and multimedia illustrations on text comprehension. International Journal of Instructional Media, 24(3), 227-238.

Onwuegbuzie A.J, Frels R. (2016), Seven Steps to a Comprehensive Literature Review: A Multimodal and Cultural Approach, Sage, 2016

Opricovic, S. (1998), Multicriteria Optimization of Civil Engineering Systems, Faculty of Civil Engineering, Belgrade, Serbia

Page, M.J., Moher, D., Bossuyt, P., Boutron, I., Hoffmann, T., mulrow, . cindy . d ., Shamseer, L., Tetzlaff, J., Akl, E., Brennan, S.E., Chou, R., Glanville, J., Grimshaw, J., Hróbjartsson, A., Lalu, M.M., Li, T., Loder, E., Mayo-Wilson, E., McDonald, S., McGuinness, L.A., Stewart, L., Thomas, J., Tricco, A., Welch, V.A., Whiting, P., McKenzie, J., (2020), PRISMA 2020 explanation and elaboration: updated guidance and exemplars for reporting systematic reviews [WWW Document]. URL osf.io/preprints/metaarxiv/gwdhk

Penttilä, H. (2006), Describing the changes in Architectural Information Technology to understand design complexity and free-form architectural expression. ITcon, (Special Issue The Effects of CAD on Building Form and Design Quality), 11, 395-408.

Pidgeon and Dawood (2021), BIM Adoption Issues in Infrastructure Construction Projects: Analysis and Solution, ITCon- Journal of Information Technology in Construction, DOI: 10.36680/j.itcon.2021.015

PriceWaterhouseCooper (2018), BIM Level 2 Benefits Measurement Methodology, Available at: https://www.cdbb.cam.ac.uk/files/3._pwc_benefits_measurement_methodology.pdf (accessed 8 June 2021)

S. Race (2012), BIM Demystified, 1st ed. RIBA Publishing, UK, London, 2012.

Rawlinson (2015), Procurement Update BIM,https://www.arcadis.com/media/D/F/5/\%7BDF5E5E67-DB174196-8FBB-

D66136F8E076\%7D9451_Simon\%20Rawlinson\%20Buildings\%20Insight\%20FINAL\%20WEB.pdf (accessed 01-08-21)

R.W. Saaty (1987), The analytic hierarchy process - what it is and how it is used, Mathematical Modelling, Volume 9, Issues 3-5, 1987, Pages 161-176, ISSN 0270-0255, https://doi.org/10.1016/02700255(87)90473-8. 
T.L. Saaty (1996), Decision Making with Dependence and Feedback: The Analytic Network Process, RWS Publ, 1996.

T.L. Saaty (2008), Decision making with the analytic hierarchy process, Int. J. Services Sci. 1 (1) (2008) 83-98.

Sandelowski, M. (2004), Using qualitative research. Qualitative Health Research, 14, 1366-1386. doi:10.1177/1049732304269672

Salgado, Purificación \& Quintana, C. \& Pereira, G. \& Ituarte, M. \& Mateos, P.. (2009), Participative multicriteria analysis for the evaluation of water governance alternatives. A Case in the Costa Del Sol (Málaga). Ecol. Econom.. 68. 990-1005.

Sanvido, V., Grobler, F., Parfitt, K., Guvenis, M., and Coyle, M. (1992), "Critical success factors for construction projects.”, Journal of Construction Engineering and Management, 118(1), 94-111.

Sebastian, Rizal \& van Berlo, Léon. (2010). Tool for Benchmarking BIM Performance of Design, Engineering and Construction Firms in The Netherlands. Architectural Engineering and Design Management. 6. 10.3763/aedm.2010.IDDS3.

Sielker, F. Allmendinger, P. (2018), International Experiences: Future Cities and BIM, Centre for Digital Built Britain (CDBB) (accessed 18/08/21)

Vishal Singh, Ning Gu, Xiangyu Wang (2011), A theoretical framework of a BIM-based multi-disciplinary collaboration platform, Automation in Construction, Volume 20, Issue 2, 2011, Pages 134-144, ISSN 0926-5805, https://doi.org/10.1016/j.autcon.2010.09.011.

Stake, R.E. (2005), Qualitative case studies. In The SAGE handbook of qualitative research, 3rd ed, ed. N.K. Denzin, and Y.S. Lincoln, 443-466. London, Thousand Oaks: Sage Publications.

Strauss, A., \& Corbin, J. (1994). Grounded theory methodology: An overview. In N. K. Denzin \& Y. S. Lincoln (Eds.), Handbook of qualitative research (p. 273-285). Sage Publications, Inc.

Succar, Bilal \& Sher, Willy \& Williams, Anthony. (2012), Measuring BIM Performance: Five Metrics. Architectural Engineering and Design Management. 8. 120-142. 10.1080/17452007.2012.659506

Suermann, P.C., Issa, R.R.A., \& McCuen, T.L. (2008, 16-18 October). Validation of the U.S. National Building Information Modeling Standard Interactive Capability Maturity Model. Paper presented at the $12^{\text {th }}$ International Conference on Computing in Civil and Building Engineering, Beijing, China.

Abu Taha, Rimal \& Daim, Tugrul. (2013), Multi-Criteria Applications in Renewable Energy Analysis, a Literature Review. Research and Technology Management in the Electricity Industry. 60. 17-30. 10.1007/978-1-4471-5097-8_2.

Tan, Tan \& Mills, Grant \& Papadonikolaki, Eleni \& Liu, Zhening. (2021). Combining Multi-Criteria Decision Making (MCDM) Methods with Building Information Modelling (BIM): A Review. Automation in Construction. 121. 10.1016/j.autcon.2020.103451.

Tavares, Rodrigo \& Galea, E.R.. (2009), Evacuation modelling analysis within the operational research context: A combined approach for improving enclosure designs. Building and Environment - BLDG ENVIRON. 44. 10.1016/j.buildenv.2008.07.019.

Taylor, J. E. (2007). "Antecedents of Successful Three-Dimensional Computer-Aided Design Implementation in Design and Construction Networks." Journal of Construction Engineering and Management, 133(12), 993-1002

Tracy, S. J. (2010), Qualitative quality: Eight "big-tent” criteria for excellent qualitative research. Qualitative Inquiry, 16, 837-851. doi:10.1177/1077800410383121

UK BIM Alliance (2020), UK BIM Framework (accessed 18/08/21)

UK BIM Framework (2018), The overarching approach to implementing BIM in the UK, https://www.ukbimframework.org/ (accessed 03 August 2021) 
Ustinovičius, Leonas \& Puzinas, Arūnas \& Starynina, Jovita \& Vaišnoras, Mantas \& Černiavskaja, Oksana \& Kontrimovičius, Robertas. (2018), Challenges of BIM technology application in project planning. Engineering Management in Production and Services. 10. 15-28. 10.2478/emj-2018-0008.

R. Volk, J. Stengel, F. Schultmann, Building Information Modeling (BIM) for existing buildings-Literature review and future needs (2014), Automation in Construction 38 (2014), pp. 109-127.

Wolf, J. (2011), Encyclopaedia of Survey Research Methods, Thousand Oaks, Sage Publications Inc

World Economic Forum (2016), Global Information Technology Report.

D. Zuppa, R. Raja, A. Issa, P.C. Suermann (2009), BIM's impact on the success measures of construction projects, Computing in Civil Engineering 503-512. 